San Jose State University

SJSU ScholarWorks

Dissertations

Master's Theses and Graduate Research

Spring 2019

\title{
Experiences of Adolescent Refugee Students Who Attend Afterschool Programs for Literacy Support
}

Analiza Filion

San Jose State University

Follow this and additional works at: https://scholarworks.sjsu.edu/etd_dissertations

\section{Recommended Citation}

Filion, Analiza, "Experiences of Adolescent Refugee Students Who Attend Afterschool Programs for Literacy Support" (2019). Dissertations. 30.

DOI: https://doi.org/10.31979/etd.2fya-a7yd

https://scholarworks.sjsu.edu/etd_dissertations/30

This Dissertation is brought to you for free and open access by the Master's Theses and Graduate Research at SJSU ScholarWorks. It has been accepted for inclusion in Dissertations by an authorized administrator of SJSU ScholarWorks. For more information, please contact scholarworks@sjsu.edu. 


\title{
EXPERIENCES OF ADOLESCENT REFUGEE STUDENTS WHO ATTEND AFTERSCHOOL PROGRAMS FOR LITERACY SUPPORT
}

\author{
A Dissertation \\ Presented to \\ The Faculty of the Educational Doctoral Program in Educational Leadership \\ San José State University \\ In Partial Fulfillment \\ of the Requirements for the Degree \\ Doctor of Education
}

by

Analiza Filion

May 2019 
(C) 2019

Analiza Filion

ALL RIGHTS RESERVED 
The Designated Dissertation Committee Approves the Dissertation Titled

EXPERIENCES OF ADOLESCENT REFUGEE STUDENTS WHO ATTEND AFTERSCHOOL PROGRAMS FOR LITERACY SUPPORT

\author{
by \\ Analiza Filion

\begin{abstract}
APPROVED FOR THE EDUCATIONAL DOCTORAL PROGRAM IN EDUCATIONAL LEADERSHIP
\end{abstract}

SAN JOSÉ STATE UNIVERSITY

May 2019

Robert Gliner, Ph.D.

Ed.D. Leadership Program

Carlos Garcia, Ph.D.

Sociology and Interdisciplinary Social Sciences

David Villegas, Ph.D.

Santa Clara County Office of Education 


\title{
ABSTRACT \\ EXPERIENCES OF ADOLESCENT REFUGEE STUDENTS WHO ATTEND AFTERSCHOOL PROGRAMS FOR LITERACY SUPPORT
}

\author{
by Analiza Filion
}

Studies on the academic achievement of refugee students cite continuous underachievement in literacy skills. Due to trauma from fleeing their countries of origin, limited school experiences, and language barriers, refugee students struggle with demonstrating progress in academic achievement. Learning challenges continue to take place when classroom teachers are not equipped with the knowledge, skills, and resources to support students with their unique learning needs. Through the use of a documentary research method, this dissertation investigated the experiences of five adolescent refugee students who attended afterschool programs as an additional resource for developing literacy skills. This study also explored how students perceived safety within the afterschool program environment. Due to the limited studies available based on the viewpoint of the students, this study described the most helpful strategies based on the students' perspectives. Culturally responsive and trauma-informed practices were used as the conceptual lens for this exploratory study. The documentary film Creating Safe Learning Spaces in Turbulent Times was created to illustrate the findings from the research. Caring tutors were identified as a key factor that contributed to students' positive experiences in and perceptions of safe learning environments. 


\section{DEDICATION}

This dissertation is dedicated to my parents, who taught me the value of education, the significance of a strong work ethic, and the importance of treating others with dignity and respect. To my mother, you have always been an inspiration to me, and I will never forget the sacrifices you made so that I could continue my education. Dagiti balakad mo ket agtalinaed to nga agnanayon kaniak: "Edukasyon Iti Tulbek Ti Panagballaigi."

I would also like to dedicate this dissertation to my teachers who helped guide me during my young adulthood. Danilo Begonia, Diane Greene, and Gregory Leland, your caring behaviors will always be remembered.

I would like to acknowledge my family members, mentors, and colleagues. Gregorio, my husband and best friend, thank you for encouraging me to pursue my dream of attaining a doctoral degree and for your unwavering support and sacrifice while I completed my dissertation.

To my son Lorenzo, thank you for your patience and gleeful laughter that always greeted me when we could spend time together.

Dr. Robert Gliner, thank you for agreeing to serve as my dissertation chairperson and for believing in me and the purpose of my study. I am eternally grateful for your mentorship, patience, and wisdom. Your reassuring comments helped motivate me to persevere during some of the most challenging times while completing this study. Dr. Carlos Garcia and Dr. David Villegas, I am very appreciative of the valuable feedback and guidance provided to me during the dissertation process and for the constructive conversations during my proposal hearing and dissertation defense that resulted in 
memorable positive experiences. Dr. Rebecca Burciaga, Dr. Marcus Pizarro, and Dr. Ferdinand Rivera, thank you for challenging me to sharpen my critical lens and deepen my knowledge about issues that mattered to me most. Dr. Arnold Danzig, thank you for your leadership in developing the San José State University EdD program and for modeling how a system of care should operate. I would also like to acknowledge the EdD faculty for sharing their areas of expertise with me and helping to frame my proposal for this study.

To Cohort 3 (Coheart 3), it has been an honor to be on this journey with you over the past 3 years. Your intelligence, resourcefulness, and attentiveness to the needs of others will always be remembered. Pura Vida! Radha and Hyon Chu, thank you for your friendship and late-night motivational texts.

Last but not least, my deepest gratitude to the youth and afterschool program adults who participated in this study. I would not have completed this dissertation without your active support and willingness to share your experiences on film. 


\section{TABLE OF CONTENTS}

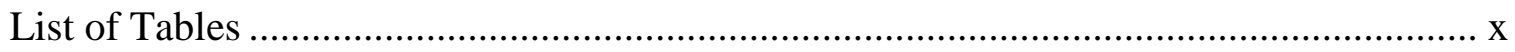

Chapter 1 Introduction and Statement of the Problem ………....................................... 1

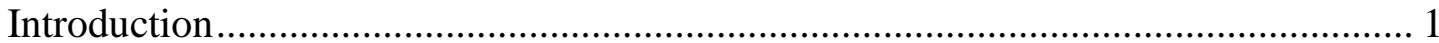

The Unresolved Issue in Education .................................................................... 2

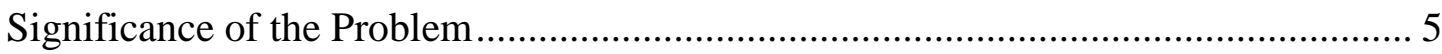

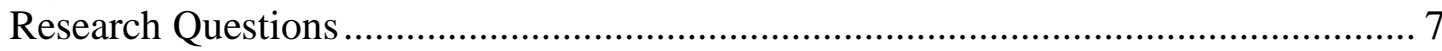

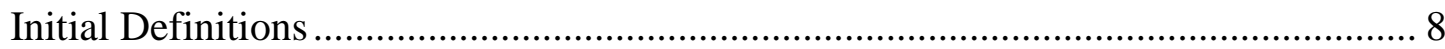

Assumptions, Background, and Role of the Researcher in the Study ……................. 9

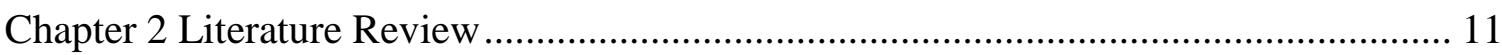

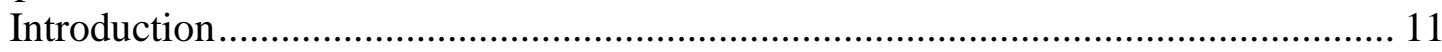

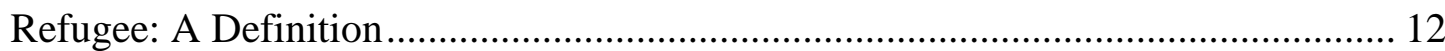

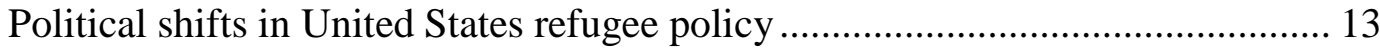

Policy shifts in United States immigration policies............................................. 15

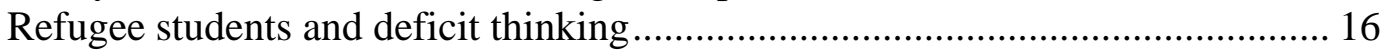

Unique Needs of Refugee Students ..................................................................... 17

Coping with trauma................................................................................ 18

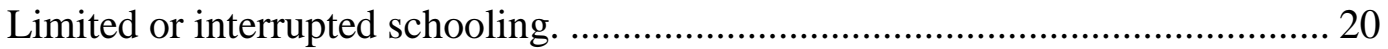

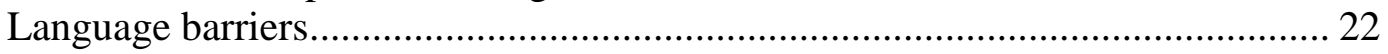

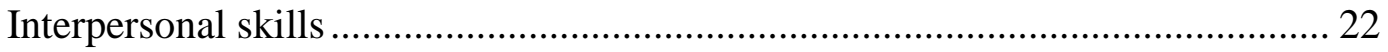

Parent-teacher relationships. .................................................................. 23

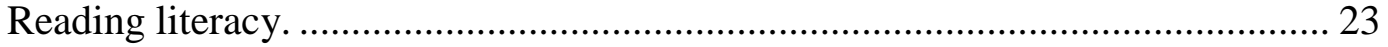

Lack of teacher preparation. ............................................................................ 24

Supporting the Educational Needs of Refugee Students ......................................... 25

Trauma-informed practices.............................................................................. 26

Guided reading and running records for literacy development. .......................... 28

Teacher-created resources for vocabulary development...................................... 30

Use of afterschool programs for developing literacy and language skills............ 33

Promising practices for refugee afterschool programs. .......................................... 34

Afterschool programs and English language development. ................................ 36

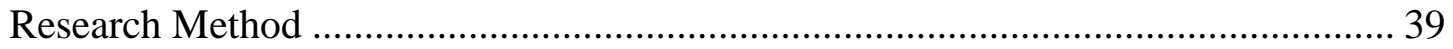

Conceptual Framework .......................................................................................... 41

Culturally relative, responsive, and sustaining pedagogies................................ 42

Gay's culturally responsive teaching framework. .............................................. 44

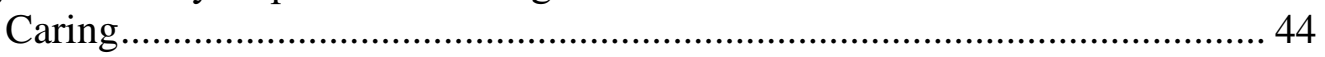

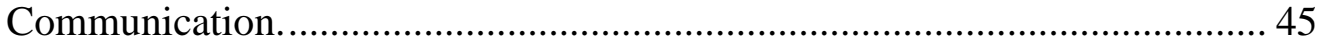

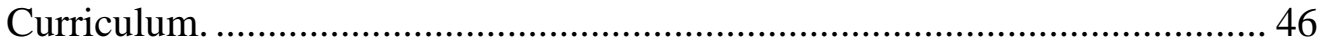

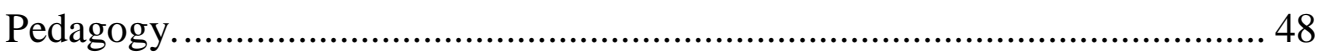

Literacy, English, and Academic Development Program...................................... 49

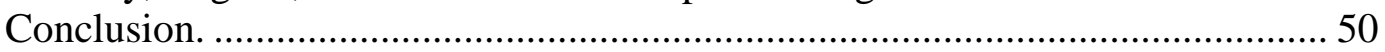

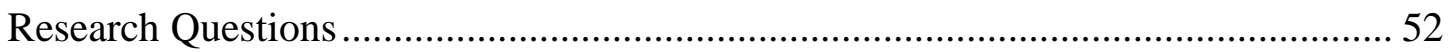


Chapter 3 Research Design and Methodology …………............................................ 53

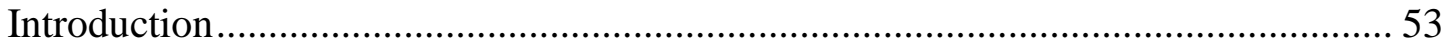

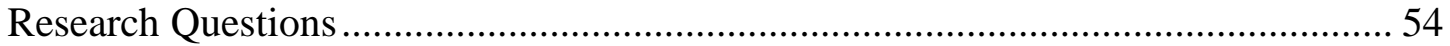

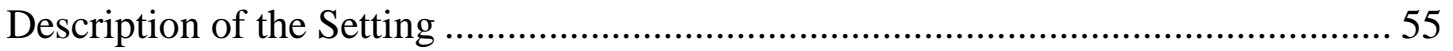

Sacred Heart Education Center............................................................................. 55

Eritrean Community Center......................................................................... 56

Catholic Charities of Santa Clara County....................................................... 57

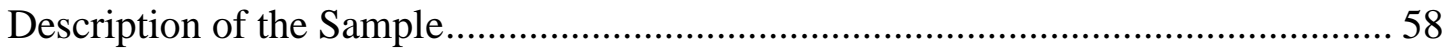

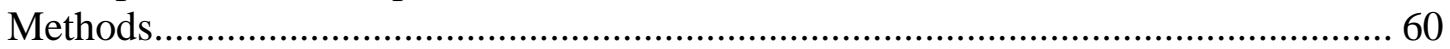

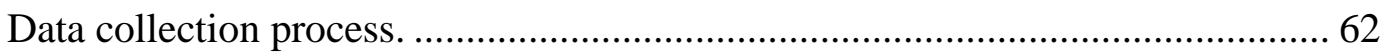

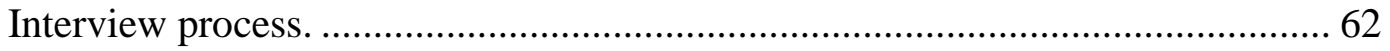

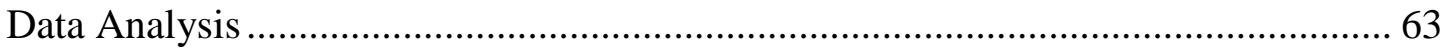

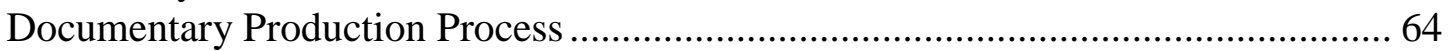

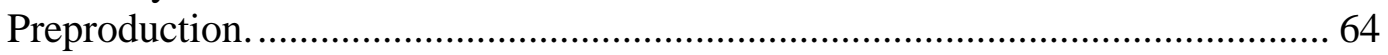

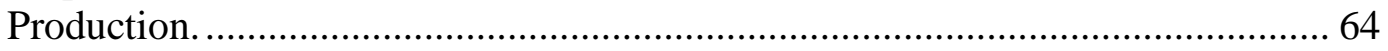

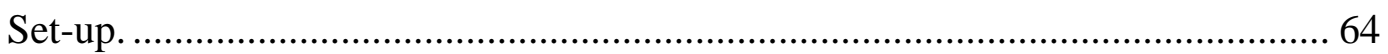

Interviews, participant interactions, and the learning environment................. 65

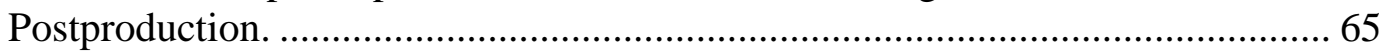

Analyzing and coding interviewee responses............................................... 66

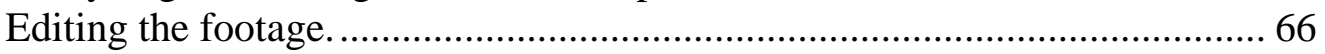

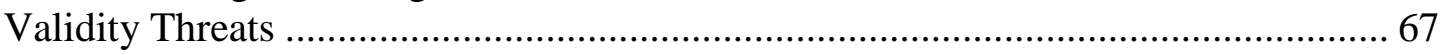

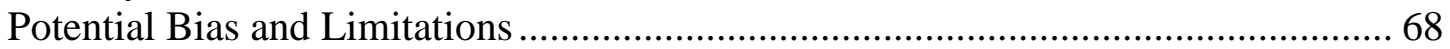

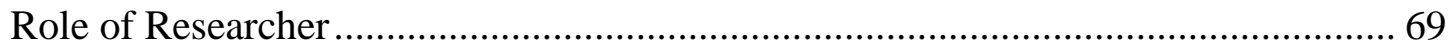

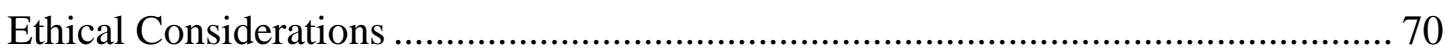

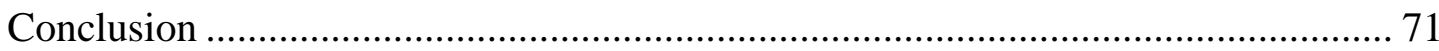

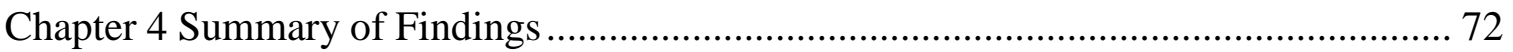

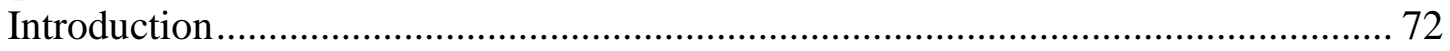

Creating Safe Learning Spaces in Turbulent Times ................................................. 72

Research Question 1: Experiences with literacy support.................................... 72

Research Question 2: Perceptions about safety. ................................................ 74

Footage not found in the documentary. ............................................................. 75

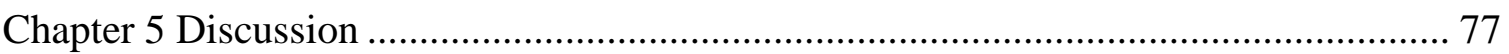

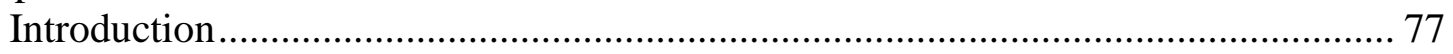

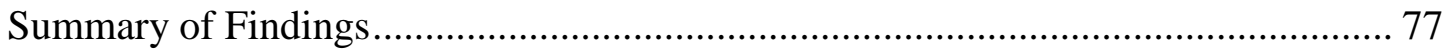

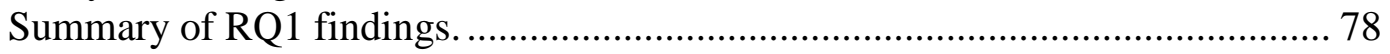

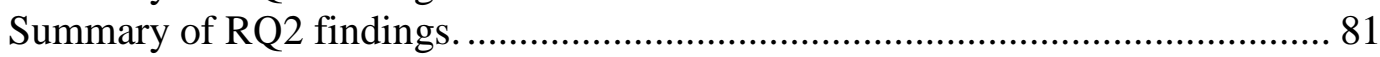

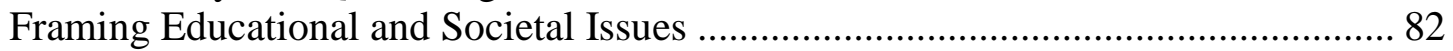

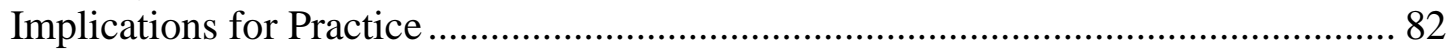

Recommendations for Future Research ………………...................................... 84

Implications for Educational Leadership ............................................................... 85

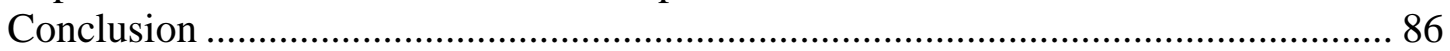

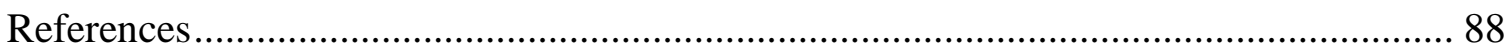




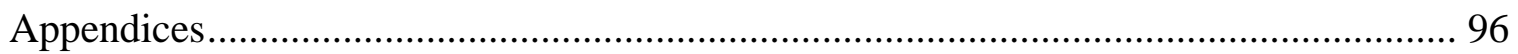

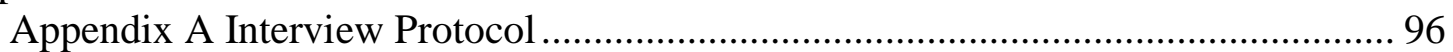

Appendix B Interview Guide for Former Tutoring Student ...................................... 99

Appendix C Interview Guide for Program Director/Tutor .......................................... 101

Appendix D Release for Participation in Documentary Film.................................... 102 


\section{LIST OF TABLES}

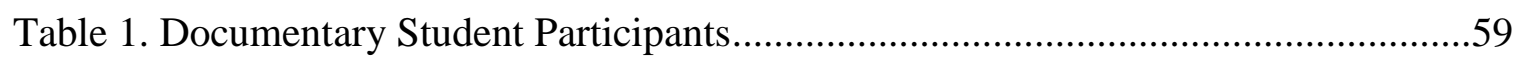

Table 2. Other Documentary Participants....................................................................61 


\section{Chapter 1 \\ Introduction and Statement of the Problem}

\section{Introduction}

According to the most recent United Nations High Commissioner for Refugees (UNHCR) report (2016), 65 million people were forced to leave their countries of origin in 2015. The reasons for fleeing included displacement from war or the fear of being targeted as a victim of violence because of religion, race, gender, political affiliation, or sexual orientation. During the same year, 21.3 million people around the globe were registered as possessing refugee status. Nearly half of the registered refugee population were children.

Since World War II, the United States has actively provided resettlement for refugees around the world. The UNHCR states that the United States has helped transition individuals from refugee status to permanent resident status more than any other country (UNHCR, 2014). During 2012, approximately 76,000 refugees gained entry into the United States (Refugee Processing Center, 2017). The majority of refugees originated from the countries of Somalia, Burma, Ukraine, Cuba, and Bhutan. From 2013 through 2015, the number of refugees entering the United States remained at approximately 70,000 per year. The majority of the population from 2013-2015 came from Somalia, Burma, Ukraine, Cuba, and Iraq. In 2016, there was an increase in refugee entries, with 85,000 entering the United States during the year (Migration Policy Institute, 2017; Refugee Processing Center, 2017). The countries of origin changed as well, with the majority of refugees originating from the Democratic Republic of Congo, Burma, Ukraine, and Columbia. 
From 2013-2015, California, Michigan, New York, and Texas housed the largest number of refugees (Office of Refugee Resettlement, 2017). According to the California Department of Social Services, from 2013-2016, the California counties that housed the most refugees included Los Angeles, San Diego, and Sacramento (California Department of Social Services Refugee Programs Bureau, 2017).

The United Declaration of Human Rights, which was drafted by members of the United Nations and world leaders on December 10, 1948, describes 30 rights that must be provided to all individuals (United Nations General Assembly, 1948). Article 26 of the document identifies access to education as a human right for all people. According to McBrien (2005), the UNHR states that education is a fundamental component in helping refugee children move towards "emotional and social healing" (p. 330) due to the violence and trauma that they have experienced and witnessed.

\section{The Unresolved Issue in Education}

In response to the increasing number of refugees entering the United States from 1975 through 1980, the country enacted the Refugee Act of 1980 (U.S. Senate and House of Representatives, 1980). The Refugee Act was also an attempt by the U.S. government to update the country's refugee policies to be compliant with international law. As part of the Refugee Act of 1980, the Educational Assistance Act of 1980 was enacted to support child refugees with attaining an education (U.S. Senate and House of Representatives, 1980). According to Section 302(b)(1), provisions for monetary funding are provided to refugee children for supplementary educational services, such as "English language instruction, bilingual education, and special materials and services" (para. 1). Based on 
Section 302(b)(2), the provisions also allocated funds for purchasing classroom materials, rental and construction costs, student transportation expenses, and in-service teacher training.

In addition to the implementation of the Education Assistance Act of 1980, the U.S. federal government created policies that outlined the process for refugee admissions into the education system. Before entering into the school system, refugees follow a protocol that confirms their refugee status and eligibility for services. This comprehensive procedure is governed by the Department of State's Bureau of Population, Refugees, and Migration (PRM). Once refugee status is determined, individuals receive services to help with resettlement into the country. Financial assistance, housing, English instruction, and education are a few of the services provided to them.

To fund the education for refugee children, the U.S. Office of Refugee Settlement provides state grants, called School Impact Grants, to districts that are considered highly impacted by the number of refugee students (U.S. Department of Health and Human Services, 2016). Based on the provisions of the state grants, students ages 5 to 18 are provided services, such as (a) English language instruction, (b) afterschool tutoring and summer programs, (c) bilingual counselors and interpreters, and (d) support for parents to encourage participation in their children's education.

In addition to the federally mandated Refugee Education Act of 1980 and School Impact Grants, refugee students are entitled to classroom instruction that is tailored to meet their specific needs. According to McBrien (2005), education is an essential requirement for successful resettlement, and learning institutions serve as the tool for 
helping refugee children integrate into their new communities. However, once refugee students enter the school system, teachers encounter several challenges with meeting their diverse needs.

First of all, refugee students are typically placed into grade levels based on their chronological ages (McBrien, 2005). However, in some cases, parents may not know the children's birth dates, which causes additional barriers. As a result of this, students are placed in the incorrect grade levels, which can lead to social and emotional stresses that are a result of different cognitive and physical developmental levels between the refugee students and their peers (Learner, 2012). Even when students are placed in grade levels with classmates close to their chronological ages, a strong possibility exists for students to struggle without the appropriate support from educators.

A second challenge that educators face is assessing the students' prior academic knowledge (Szente, Hoot, \& Taylor, 2006). Language barriers, literacy proficiency, and lack of writing experience are issues faced by educators when trying to gather school entrance data. Because of the challenges with correctly assessing students' prior knowledge, some refugee students are incorrectly placed into remedial courses even though they were previously enrolled in accelerated courses or gifted programs in their native countries (McBrien, 2005). Third, according to Szente et al. (2006), educators cite the lack of translator support or lack of English language learner (ELL) training as another significant barrier to understanding the academic needs of refugee students and providing them with the educational support necessary to help them develop English proficiency skills. 
Overall, policies are in place to provide refugee students with educational resources that facilitate academic success. However, based on the literature, improvement is needed with establishing reliable procedures for determining appropriate grade levels and measuring academic knowledge during the school enrollment process. Also, teachers require additional skills and resources to support ELL refugee students.

\section{Significance of the Problem}

Current studies cite a variety of criteria necessary for refugee students to achieve successful integration into the education system. Educational support with English language acquisition, mental health services, understanding the students' cultural backgrounds, and close relationships and ongoing support from refugee resettlement organizations and school sites are identified as unique needs of refugee students (McBrien, 2005; Szente et al., 2006). Acceptance by the students' peers and addressing teacher bias and negative stereotypes towards refugee students are also necessary for refugee students to be successful in the U.S. school system. Although several factors must be met to support this student population effectively, the focus of this study was on the academic needs of refugee students.

Language acquisition is critical for refugee students' academic achievement. According to McBrien (2005), refugee students value English language acquisition as a skill needed to fit successfully into the U.S. culture. McBrien identified language acquisition strategies used by educators for refugee students to include the language experience approach, which builds on the students' native language skills, English as a second language (ESL) classes, and bilingual instruction. Although the language 
experience approach is designed to build on the students' native language skills, some refugee students are reluctant to use this model since the use of their native languages reminds them of traumatic experiences from the native countries. Overall, due to the significance that English language acquisition plays in helping refugee students successfully integrate into the U.S. school system, it is critical that educators and researchers identify and implement language acquisition strategies that meet this population's specific needs.

The available research in the field of education routinely includes refugee students as part of the immigrant ELL student population. According to researchers, both groups face the challenge of learning new languages and cultures and encounter issues of discrimination and racism. However, the main difference between the two groups is the voluntary decision made by immigrant students' families to leave their countries in search of better economic or educational opportunities versus the forced decision by refugee students' families to flee their countries to escape persecution or death (McBrien, 2005). Because of these horrific events, it is critical for educators to (a) understand that this student population requires academic support, and (b) develop a better understanding of how the trauma of the refugee experience affects the academic achievement of refugee students and their ability to interact with peers (Roxas, 2011).

Although efforts are being made to understand how to best support refugee students in the U.S. school system, the student population continues to struggle with English language acquisition, which is a critical element for the students' academic achievement. 
Also, limited studies are available to describe the experiences of refugee students without having them included as part of the immigrant population in the U.S school system.

The purpose of this study was to support refugee students in improving their reading comprehension skills and vocabulary acquisition. Vocabulary development plays a critical role in attaining English language proficiency. Due to the current lack of resources to help them in the classroom, the experiences of refugee students who use afterchool programs as an additional resource for helping to develop reading comprehension skills and for understanding and use of new vocabulary were explored in this study. In addition, due to the significant role that trauma plays in students learning experiences, how culturally responsive factors affect students' perceptions about safety within an instructional setting were examined, as well as how refugee students perceive safety within the afterschool program environment.

The main challenges for educators in supporting refugee students include incorrect grade-level placement, assessing prior knowledge, and lack of teacher preparation for supporting ELLs and students who have undergone experiences with trauma. Because of these issues, there is a lack of support services available in mainstream classrooms to support refugee students in advancing in literacy skills and coping with issues of trauma.

\section{Research Questions}

This exploratory study investigated the experiences of adolescent refugee students who attend afterschool programs for literacy support and addressed the following research questions: 
1. How do culturally responsive teaching practices used in afterschool programs affect refugee students' experiences with getting literacy support?

2. What culturally responsive factors influence how refugee students who have experienced trauma perceive safety within the homework club environment?

For the purpose of this study, literacy support refers to instructional support in both reading comprehension and vocabulary acquisition skills. Since limited studies are available based on the viewpoint of the students, the most helpful strategies based on the students' perspectives were described in this exploratory study. Due to the significant role that trauma plays in the learning experiences of refugee youth, this study also investigates elements of afterschool programs that contribute to safe learning environments.

\section{Initial Definitions}

According to the 1951 Refugee Convention, a refugee is defined as possessing a "well-founded fear of being persecuted for reasons of race, religion, nationality, membership of a particular social group or political opinion" (United Nations High Commissioner for Refugees, 2010, p. 14). The 1951 Refugee Convention recognized only Europeans as the intended refugee population outlined in the document. However, the creation of the 1967 Protocol included all of the provisions of the Refugee Convention and expanded the definition of refugee by eliminating geographic limitations (United Nations High Commissioner for Refugees, 2010, p. 2).

Over the past 10 years, there has been an increase in individuals fleeing countries from Central America to the United States. In 2014, an alarming number of 
unaccompanied children from the regions of Central America fled their countries due to extreme fear of violence from organized armed criminals and fears of being recruited and exploited by human traffickers (Migration Policy Institute, 2015). In instances such as these, the definition of refugee has also been extended to include instances of humanitarian crisis or urgent humanitarian situations. For this study, refugee refers to the definition outlined by the 1951 Refugee Convention and 1967 Protocol and to individuals who flee their countries from urgent humanitarian crises due to extreme poverty, fear of violence, and human traffickers.

\section{Assumptions, Background, and Role of the Researcher in the Study}

According to the available research, refugee students continue to struggle with academic achievement due to the lack of resources available to them in the classroom. The findings from studies of afterschool programs cite the effectiveness of the programs as an additional resource for supporting the academic achievement of marginalized populations (Neuman, 2010; Sung \& Chang, 2008).

Several assumptions have been made as a result of previous studies. The first assumption is that participation in afterschool programs can serve as an outside resource to help refugee students with academic achievement. Secondly, identification of effective vocabulary acquisition instructional strategies can be used to inform classroom teachers and afterschool program teachers with teaching practices that can be duplicated in classrooms and other afterschool programs. Lastly, listening to students' experiences is a more accurate way to determine the teaching strategies that are most effective for them. 
The researcher has served as a middle school English language arts classroom teacher for 10 years. The researcher is not employed or in any way affiliated with the two organizations used in the study. The role of the researcher was to conduct exploratory research through the use of documentary work to bring attention to how afterschool programs can be used as outside resources to meet the unique needs of refugee students. The exploratory research is also intended to bring attention to the necessity of addressing refugee students as a separate group from immigrant students and to inform educational professionals about effective strategies for supporting refugee students with developing their literacy skills and providing them with safe learning environments. 


\section{Chapter 2 Literature Review}

\section{Introduction}

In this chapter, the literature related to the educational experiences of refugee students in a classroom setting is explored. The literature provides the context for the problem of practice for this study, which has been identified as a lack of educational resources available in mainstream classrooms for refugee students to support their literacy advancement. Due to the role that trauma plays within the students' learning outcomes, the literature related to support structures that have been implemented to address issues of trauma within a classroom setting is also provided.

The chapter is divided into six different sections. First, the existing definitions for refugee are provided. History of the term refugee offers context for the unique challenges faced by refugee students and classroom teachers. Second, an examination of the educational problems experienced by refugee students is given. Third, teaching interventions with an emphasis on literacy and English language acquisition that have been implemented in the classroom for refugee students are provided. Although several studies have contributed to this topic, this dissertation focused on the use of afterschool programs as a resource for improving students' literacy skills. Fourth, an overview of trauma-informed practices (TIPs) used in the classroom setting is provided to explore the support structures available to help refugee students cope with issues of trauma. Fifth, the literature related to documentary film as a research method is provided. Lastly, culturally responsive teaching (CRT) and elements from TIPs used in Canada's Literacy, English, 
and Academic Development (LEAD) program were examined, since this serves as the framework for the study.

\section{Refugee: A Definition}

For the purpose of this study, the definition of refugee includes: (a) the refugee criteria outlined by the United Nations and acknowledged as part of international law (UNHCR, 1951), (b) individuals fleeing their countries due to humanitarian crisis from fear of violence (Migration Policy Institute, 2015), and (c) persons fleeing their countries due to economic conditions that have resulted in starvation (Harris, 1993).

Based on the recent studies by the Migration Policy Institute (2015), there has been a steady increase of refugee adults and children fleeing their native countries to host countries with the hope of gaining the opportunities to rebuild their lives. According to the Commissioner-General of the United Nations Reliefs and Works Agency, more than 65 million people were displaced at the end of 2016, which has been the highest recorded number in history (UNHCR, 2016).

Public opinion about refugees continues to be a controversial topic, which, unfortunately, has manifested itself as a vehicle for deficit thinking toward refugee students. One example of how public opinion affects the perceptions of refugees is the polarizing images based on the refugee definition. When conducting an online search for the definition of refugee, the definition provided by the UNHCR (2010) is the most typical example provided: 
[A refugee possesses] a well-founded fear of being persecuted for reasons of race, religion, nationality, membership in a particular social group or political opinion, is outside the country of his nationality and is unable or, owing to such fear, is unwilling to avail himself of the protection of that country; or who, not having a nationality and being outside the country of his former habitual residence, is unable or, owing to such fear, is unwilling to return to it. (UNHCR, 2010, p. 10)

The original definition of refugee was created for individuals who were fleeing the Communist regimes of Eastern Europe during the Cold War (Taylor \& Sidhu, 2012). During this time, refugees were viewed as "freedom fighters" (Taylor \& Sidhu, 2012). However, after the Cold War, refugees were no longer viewed as heroes, but instead, were portrayed as "subject(s) of underdevelopment from Third World Countries" (Taylor \& Sidhu, 2012, p. 41).

Political shifts in United States refugee policy. The change in U.S. political policy on refugee settlement has resulted in multiple political conflicts and negative stereotypes towards refugees. The differing political viewpoints on refugee resettlement policy between President Obama and President Trump exemplifies this striking contrast. In 2015, President Obama pledged to admit 80,000 refugees during the fiscal year 2016 and increase the number to 110,000 in the fiscal year 2017 (Migration Policy Institute, 2015). President Obama's promise to increase the refugee ceiling resulted in massive support from numerous humanitarian organizations. However, the proposed limit increases also led to widely publicized criticism due to fears that refugees would pose a threat to the United States. 
To address the criticism of the proposed increase in refugee admittance numbers, President Obama made the following public response during a November 2015 Weekly Address:

Nearly four centuries after the Mayflower set sail; the world is still full of pilgrims ... men and women who want nothing more than the chance for a safer, better future for themselves and their families. What makes America America is that we offer that chance. (para. 8)

In January 2017, newly elected President Trump signed Executive Order 13759: Protecting the Nation From Foreign Terrorist Entry Into the United States. The executive order negatively impacted refugees hoping to gain entry into the United States. As a result of the executive order, several directives were proposed, including: (a) temporary suspension of the U.S. Refugee Resettlement program for 120 days, (b) reduction of the refugee admission ceiling during for fiscal year 2017 from 110,000 to 50,000, (c) suspension of U.S. entry for Syrian refugees, and (d) orders for "prioritizing the claims of religious-based persecution by applicants who are religious minorities in their country" (Cowger, Bolter, \& Pierce, 2017, p. 1). In addition to the limitations placed on refugee settlement, the executive order also suspended citizens from Iran, Iraq, Libya, Somalia, Sudan, Syria, and Yemen from entering the country and implementation of an extreme vetting process for all new applicants seeking admission to the United States (Cowger et al., 2017).

President Trump's executive order on the travel ban and refugee settlement resulted in mass protests. Public demonstrations were widely covered by national media in support of refugees seeking to enter the country. Demonstrators who agreed with the president's orders were also given news coverage. 
In February 2017, a temporary restraining order was placed on President Trump's executive order (Cowger et al., 2017). At the present time, President Trump's executive order continues to be in dispute within the U.S. court system, and several revisions have been made to the original executive order, which includes the removal of Iraq from the list of countries suspended from entering the United States and expanding the travel ban to citizens from the countries of Chad, North Korea, and Venezuela (Bolter \& Chishti, 2019).

Other policies created during the Trump presidency include a halt to the Central American Minors Refugee and Parole Program, which allowed parents who were lawfully living in the United States to file refugee resettlement interview requests for their children (Pierce, Bolter, \& Selee, 2018). In addition, temporary protected status (TPS), which included temporary "humanitarian protection" (p. 16) to individuals fleeing their countries due to violence or natural disasters, also ended for nationals from the countries of El Salvador, Haiti, Nicaragua, and Sudan.

Policy shifts in United States immigration policies. During President Trump's first year in office, several shifts also took place in regard to immigration policies. Many of the changes were initially proposed during President Trump's 2016 presidential candidate speech in Arizona, which led to numerous protests from immigrant communities. One of the modifications included the criminal prosecution rather than deportation of individuals illegally entering the United States (Pierce et al., 2018). In May 2018, the Trump administration announced a zero-tolerance policy that included the criminal prosecution 
of all migrants attempting unlawful entry in the country, including asylum seekers with children (Barajas, 2018).

Two weeks after the policy was announced, 638 adults - who were accompanying 658 children - were detained and prosecuted. During the time that the policy was enforced, minors traveling with detained adults were transferred to the Office of Refugee Resettlement, which assisted with assigning sponsors for the children while their parents or caregivers underwent court proceedings. The separation of children from parents or caregivers resulted in numerous protests and negative media coverage. In June 2018 , President Trump signed an executive order to end the act of separating families and replaced it with detaining families together. At present, the efforts and success of reuniting children with their families and maintaining detention centers that house families together continue to be a challenging process for the Trump administration.

Other policies established by the Trump administration include: (a) expanding the border wall between Mexico and the United States and increasing the number of border patrol agents, (b) increasing the role and presence of U.S. Immigration and Customs Enforcement (ICE) authorities with locating and detaining undocumented individuals, and (c) terminating federal grants to "sanctuary cities" and "sanctuary states" (Pierce et al., 2018, p. 12). Sanctuary cities and states are described as cities and states that provide limited cooperation to ICE with regard to implementing immigration policies.

Refugee students and deficit thinking. Unfortunately, the racism and deficit thinking towards refugee populations seeking entry to the United States do not stop at public criticism or policy mandates. Refugee children also endure deficit thinking and 
racism in the classroom. Jonas and Rutter found that "resources for refugee education were inadequate, and that refugee children were often seen as 'problems' - rather than having the potential to bring positive elements into the classroom" (as cited in Taylor \& Sidhu, 2012, p. 43). In addition, the refugee student population is commonly labeled as traumatized and poorly prepared for school rather than acknowledged for theskills and talents that they possess (Ogilvie \& Fuller, 2016; Roxas, 2008). A study by Roberts and Locke (2001) found that refugee students were being characterized as "disabled" (p. 378) and strongly recommended to stop speaking their primary languages.

The literature on refugee students illustrates the need to address the psychological and emotional needs of these students. However, limited information is provided on the strengths and skills that refugee students bring to their new school activities. For example, refugee students possess coping strategies that they have developed due to the refugee experience. Roxas (2008) stated that the lack of teacher familiarity with refugee students "can lead teachers to undervalue the courage, tenacity, and resourcefulness" (p. 5) possessed by the student.

Overall, along with being violently uprooted from their native countries and forced to seek safety in new countries, refugee adults and children endure more challenges in their new countries where they are often portrayed as "helpless" and labeled as problematic (Roberts \& Locke, 2001).

\section{Unique Needs of Refugee Students}

The United Declaration of Human Rights stipulates that access to education is a human right for all people (United Nations General Assembly, 1948). School is identified 
as a critical component in supporting refugee children with successful refugee resettlement and an essential element in helping them heal from the refugee experience (McBrien, 2005). The studies on the educational experiences of refugee students cite several common unique challenges faced by this student population. However, the issues addressed in this paper were limited to a brief review of four common challenges faced by refugee students in the classroom: (a) coping with trauma, (b) limited or interrupted schooling, (c) language barriers, and (d) lack of teacher preparation. Because of these difficulties, it is important that educators are provided with the tools necessary to support these students emotionally, psychosocially, and academically.

Coping with trauma. One common problem faced by refugee students is the psychological, social, and emotional trauma from experiences of fleeing their countries of origin (Ogilvie \& Fuller, 2016; Roxas, 2011; Szente et al., 2006; Taylor \& Sidhu, 2012). Some refugee girls have reported experiences as child brides, while some refugee boys have described their experiences as child soldiers before fleeing their countries (Roxas, 2011). In situations where the children's parents died due to malnutrition, illness, or war, the children became head of the households and were responsible for taking care of their siblings.

Trauma occurs from either direct involvement with the traumatic event or from being an eyewitness. Secondary traumatic stress can occur through learning about traumatic circumstances that involve attachment figures, such as family members or caregivers (Record-Lemon \& Buchanan, 2017). The work from Cohen, Mannarino, and Deblinger (as cited in Record-Lemon \& Buchanan, 2017) asserted childhood trauma is associated 
with negative impacts to brain function and development, mental health, and emotion regulation (West, Day, Somers, \& Baroni, 2014). Learning challenges, such as the inability to communicate and process or memorize information, have been reported. Anxiety, depression, attention difficulties, and posttraumatic stress disorder have also been linked to impacts from trauma. In addition, challenges with emotional selfregulation have resulted in difficulties with establishing appropriate boundaries, controlling impulses, and managing emotions. Unfortunately, background information on new refugee students is not always readily available for teachers, which makes it difficult for them to assist students with issues of trauma (Szente et al., 2006).

Although counselors work with refugee students to help them cope with trauma, some parents of refugee children are hesitant about allowing their children to visit with counselors since counseling sessions are not a common practice in their native countries, and they do not understand how counseling sessions are helpful for addressing their children's trauma (Szente et al., 2006). Due to the significant role that trauma plays in the developmental and learning experiences for students, increasing attention has been given to the role that schools and TIPs play in supporting students who have experienced trauma (Cohen et al., 2006; Record-Lemon \& Buchanan, 2017; West et al., 2014).

Record-Lemon and Buchanan (2017) conducted a literature review of the international research available for TIP in school settings. The four models of TIP identified in the literature included trauma assessment, trauma support, program implementation and evaluation, and trauma intervention. As part of the literature review, the models were examined for common themes. 
First, Gonzales, Monson, Solis, Jaycox, and Langley found that a significant number of school-age children had experienced traumatic events (as cited in Record-Lemon \& Buchanan, 2017). In addition, schools were found to play a significant role in how students experienced the impact of trauma (Dods, 2015; West et al., 2014). Secondly, supportive, caring, and respectful relationships and TIP resources were identified as important support structures for children and adolescents who had experienced trauma. On the other hand, West, Day, Somers, and Baroni (2008) found that certain images, words, noises, and interactions were found to be triggers that resulted in "trauma-related symptoms" (as cited in Record-Lemon \& Buchanan, 2017, p. 298).

Limited or interrupted schooling. A second challenge faced by refugee students when transitioning to the U.S. education system is limited school experience. The educational history of refugee students is reported to range from nonexistent to limited. Interrupted schooling is another type of school history experienced by students (Roberts \& Locke, 2001; Szente et al., 2006; Taylor \& Sidhu, 2012). According to a parent of refugee children, the previous educational experiences of refugee children could be described by two different categories:

One type has never been to school before since their lives thus far were about "running and hiding." The other type may have had some school experiences, but those might differ greatly from school experiences in America. (Szente et al., 2006, p. 18)

Because of the wide range of school experiences that refugee children bring with them to the classroom, it is important that educators understand that the students' ages do not necessarily match up with the corresponding grade levels. For example, teachers have reported instances where students did not know how to use a crayon or hold a book since 
they did not have any prior educational experiences (Szente et al., 2006). Older students have also been placed in classrooms with younger students because of the results from the refugee placement tests at their new schools. According to Trueba (1987), placing older students in the same grade level as younger students negatively impacts their selfesteem, future outlooks on school, and "competency to work at their capacity" (p. 386). Unfortunately, for many refugee students who enter the U.S. education system, students' grade-level placements are based on assessments that are given in English rather than their native languages.

In addition to learning to adjust to sitting in an indoor classroom or attending classes with younger students, students are also faced with the challenge of learning how to navigate the U.S. school system. Many refugee students have to transition to different norms and procedures than they experienced in their country of origin. One 13-year-old female student from Iran described how she had no prior experience with the English language or the "historical and social tenets" (Robert \& Locke, 2001, p. 381) of the U.S. system. To learn to navigate her way through the new school environment and improve her English language skills, the student relied on informal interactions with her classmates.

In summary, the school experience for refugee students in their new educational environments is dependent on multiple factors. Roberts and Locke (2001) identified student age and level of past education as significant factors affecting accurate assessment of refugee student language and reading skills and delivery of developmentally appropriate instruction. The level of teacher preparation is also 
designated as a critical element for determining the future school experience of refugee students.

Language barriers. A third challenge faced by refugee students is language barriers (Ogilvie \& Fuller, 2016; Roberts \& Locke, 2001; Szente et al., 2006; Taylor \& Sidhu, 2012). According to Roberts and Locke (2001), "Students who are not grounded in the mainstream culture struggle to get along in school settings that are institutionalized according to the moral, social, and cultural dimensions of society" (p. 376). The literature on refugee children has cited language barriers as one of the main challenges in adjusting to new school cultures. Three problems that students endure because of language barriers are discussed: (a) lack of interpersonal skills to form bonds with classmates and teachers, (b) limited support from family members, and (c) difficulty with understanding school content. Educators must be experienced with helping students develop their English language skills to help refugee students successfully integrate into mainstream culture.

Interpersonal skills. As a result of language barriers, refugees must navigate through their new school environments with limited interpersonal skills. Interpersonal skills are critical for helping students develop relationships with fellow students and teachers. Through peer and teacher relationships, students gain insight into school norms and expectations, social and cultural capital, and support with academic achievement. Cummins (1981) determined that basic interpersonal communication skills are necessary for students to achieve "successful personal and social interaction" (p. 382). Also, strong basic interpsonal communication skills are needed for a successful transition into 
mainstream classrooms where students will be expected to communicate with teachers and fellow students as part of the learning experience.

Parent-teacher relationships. Strong parent-teacher relationships that involve clear and consistent communication are also critical for helping refugee students adjust to their new school communities (Szente et al., 2006). Unfortunately, refugee parents have reported not attending school meetings due to their inability to understand their children's teachers or administrators. Other commitments, such as social worker meetings, work schedules, and mandatory English language classes are reasons for not attending school meetings. The use of translators during parent/teacher meetings, written communication from teachers to students' parents, and home visits are helpful for encouraging parents to attend school events (Szente et al., 2006).

Reading literacy. The spoken and written forms of students' native languages and new language literacy expectations are two challenges commonly faced by refugee students. Many students speak native languages that possess a spoken and written form. However, some languages may have a spoken form but no written form (Montero, Newmaster, \& Ledger, 2014). In other instances, students may speak more than one language but not be literate in any language. For example, a group of African refugee students who resettled in Australia spoke a tribal language and Arabic. However, the students possessed either minimal or no reading skills (Miller, 2009).

Although some ELLs can quickly acquire oral language proficiency, Miller (2009) asserted the acquisition of this skill has been "misleading for mainstream teachers" ( $\mathrm{p}$. 573) who assume that oral language proficiency translates to a smooth acquisition of 
academic skills. Miller found that even after a group of refugee students acquired the new language skills necessary to transition to their mainstream classrooms, the students struggled to understand the texts they were reading because many of them were not literate in their first language. Students with limited or no schooling struggle academically due to lack of literacy skills required to understand subject content, types of genre, and learning strategies to analyze the text they are reading (Naidoo, 2009).

Refugee students from the study by Brown, Miller, and Mitchell (2006) identified science and social studies as the most problematic subjects. The classroom teacher who contributed to the study wrote, "The students stressed that the language of [the two] subjects ... was extremely difficult, the textbooks too hard, and that their content area teachers did not help them with the language" (as cited in Miller, 2009, p. 572).

Lack of teacher preparation. Refugee students are dependent on classroom educators to support them in transitioning to their new school environments and making gains in academic achievement. However, teachers have reported feeling unprepared to work with students who have limited English skills (Szente et al., 2006). Although teachers understood their role to provide close assistance for refugee students, they found it difficult to balance providing the additional support for refugee students and the other students in the classroom.

One teacher's first encounter with a new refugee student in the class was described as the following:

Then I got this child. I soon found out that she never attended school ... I do not have training to ... [work with students with limited English skills]. I was initially very frustrated because I felt divided in trying to help both the refugee child and the rest of the class. (Szente et al., 2006, p. 18) 
Montero et al. (2014) found that high school teachers who worked with refugee adolescent students reported that they were not prepared to provide early literacy instruction for them since "the instructional practices at the high school level were more geared towards instructional practices that assumed dominant language literacy abilities" (p. 60). Teachers also reported difficulties with assessing the students' academic achievement and administering mandatory refugee placement tests.

Refugee students experience several unique educational challenges that must be addressed to support them in attaining successful resettlement. Three main problems faced by students include: (a) coping with trauma, (b) limited educational experience, and (c) language barriers. As the literature suggests, language barriers continue to be a major issue for refugee students, which has resulted in underachievement of literacy proficiency. This issue is impacted by the fact that teachers have reported feeling unprepared to support these students.

\section{Supporting the Educational Needs of Refugee Students}

The research on the educational experiences of refugee students concludes that students struggle in their new educational environments due to experiences of trauma, interruptions in formal education, no prior schooling experience, or poor quality of education (Montero et al., 2014). These factors have contributed to the negative impacts

on refugee students' literacy. The literature also indicates the struggles of mainstream and ELL teachers who do not feel prepared to support refugee students with the existing classroom curriculum and resources (Miller, Mitchell, \& Brown, as cited in Miller, 2009; Montero et al., 2014; Szente et al., 2006). 
To address this area of academic concern, educators and researchers have integrated intervention strategies that target early literacy skills and language development. Traumainformed practices is also a growing area of interest for educators and researchers to help provide students' who have experienced trauma with a caring and safe learning environment. Afterschool programs have also been identified as a promising resource for improving students' literacy development, which serves as the focus of this dissertation. Due to the underlying issue of trauma that exist within this student population, an investigation of factors that contribute to students' perceptions of safety within an afterschool program environment is also examined.

Trauma-informed practices. Miles and Bailey-McKenna (2016) investigated the use of the LEAD program as a framework for supporting the educational needs of refugee students resettling in Canada. The case study incorporated a hypothetical student's experiences as a participant in the LEAD program. Efforts have been made to collect quantitative data on student achievement; however, an analysis of the data has not been completed at this time. The success of the program is based on anecdotal reports from multiple stakeholders, which include the viewpoints of students, parents, and teachers.

Three critical components of the LEAD program included English language development (ELD), TIP, and cultural responsiveness. First, the ELD program consists of four main elements: (a) cultural responsiveness to students' experiences, (b) language and culture, (c) personalized learning, and (d) explicit daily English instruction. The use of visual and hands-on teaching materials, the frequent practice of oral language skills, and ongoing review of vocabulary words were identified as effective scaffolding strategies 
for ELD. Second, the LEAD program's TIPs are grounded in four components: (a) assisting students with attaining basic and socioemotional needs and mental health support; (b) implementing a "trauma-responsive framework" (Miles \& Bailey-McKenna, 2016, p. 119), (c) helping students manage their emotions, and (d) using a multidisciplinary system to provide the necessary supports for students. Third, LEAD staff employ culturally responsive strategies to provide opportunities for students to develop a sense of belonging and empowerment by incorporating students' backgrounds and experiences within the students' learning opportunities and classroom resources.

The attachment-regulation-competency (ARC) framework and bottom-up intervention methods are two key components of LEAD's TIPs. Developed by Blaustein and Kinniburgh (2016), the ARC framework is based on the premise that school staff must maintain a calm state at all times since their emotions set the tone for the classroom environment (as cited in Miles \& Bailey-McKenna, 2016). In addition, children who have experienced trauma are attentive to nonverbal cues that take place around them.

The bottom-up approach is a three-stage strategy used by LEAD staff to help students regulate their emotions. Each stage must be completed before moving on to the next stage. The first stage includes helping students regulate their emotions through methods such as muscle relaxation and yoga, which is then followed by the bonding and community-building phase. Once this step is completed, school staff then focus on accessing and developing students' cognitive and metacognitive skills.

Overall, the study presented several promising strategies for supporting the unique needs of refugee students. At this time, insufficient data are available to measure the 
efficacy of the LEAD program. However, according to Miles and Bailey-McKenna (2016), efforts are being made to collect quantitative and qualitative data to analyze trends and determine how to improve the program to better meet the needs of students. In addition, limited information was provided in the study with regard to how the program provides a safe learning environment for students.

As a result of the study, several insights were made by the authors for strengthening the LEAD program. Maintaining high expectations for English language learning in the classroom and preventing duplication of services through a case management system were identified as areas of improvement. Designing effective student transportation systems and processes for recognizing students that require more intensive academic support due to issues such as cognitive delays were also areas needing improvement.

Guided reading and running records for literacy development. Montero et al. (2014) investigated the need to address gaps in literacy proficiency for adolescent refugee students through the use of early literacy practices. The study included a sample size of 11 refugee students who ranged from ages 14-20. All students were enrolled in an ELD program in a Canadian public school.

Studies on literacy development found guided reading was successful as an instructional practice to help all students learn to process text that they are reading (Iaquinta, 2006; Montero et al., 2014). Through guided reading, teachers model fluency and examples of how to interact with the text. The strategy also allows teachers to observe students' fluency and strategy for understanding the text they are reading. Guiding reading also emphasizes that students interact with the content through three 
different modalities: "oral language, reading, and writing activities" (Montero et al., 2014, p. 62). By using guided reading, students acquire the skills needed to become independent and skilled readers.

Running records was the second intervention strategy implemented for the sample group. Through running records, teachers can monitor their students' reading behaviors. Examples of observable reading behaviors include decoding strategies, types of miscues, self-monitoring and self-correcting actions, and intonation. This approach also allows teachers to observe the students' cognitive processes and offer correct instructional support. Also, running records provide teachers with the information needed to track student progress.

As a result of implementing guided reading and running records with the refugee students for 5 months, the student running record scores showed that students achieved reading gains that ranged from three to 13 levels (Montero et al., 2014, p. 65). The overall average reading gain was 8.3 levels. Based on the teacher's previous class where the two intervention strategies were not implemented, and the students possessed similar student profiles to the student sample, student running records showed that the refugee students' reading gains over a 5-month period ranged from zero to three levels. The overall average reading gains were 1.2 levels (Montero et al., 2014, p. 65).

As a result of the study, the authors suggest that the best way to support adolescent refugee students with literacy development is through the use of focused literacy rather than traditional language programs (Montero et al., 2014; Woods, 2009). The authors' study provides valuable information about the need to address the literacy gaps 
specifically for adolescent refugee students. Since adolescent students have limited time to develop proficient literacy skills before they age out of public education, purposeful and evidence-based effective practices to assist them are needed. According to Collier (1989), ELLs acquire academic language proficiency within 5 to 7 years (as cited in Montero et al., 2014, p. 67).

As part of the intervention, Montero et al. (2014) cited the integration of culturally responsive text for the students. The purpose was to provide refugee students with a curriculum that reflected the personal experiences of refugee students. However, the teacher was limited to some age-appropriate culturally responsive texts for the students to use during the intervention. More investigation is needed to determine how a broader range of age-appropriate culturally responsive curriculum affects the reading achievement of refugee students, which is an area of investigation for this study.

Teacher-created resources for vocabulary development. Miller (2009) investigated the challenges that ELL students faced with transitioning to mainstream high school classrooms in Australia after completing 1 year of intensive English language instruction. The focus of the study included refugee students who experienced interrupted schooling and their struggles with understanding the science curriculum, primarily due to the lack of vocabulary acquisition in the content area. The sample group included 23 students, many of which were not literate in their first language. However, the exact number of nonliterate students was not provided in the study.

According to Miller (2009), limited studies are available on the vocabulary development of low-literacy ELL students. The need for additional research in this area 
requires extra attention since it is critical for students to recognize over $90-95 \%$ of the vocabulary (Nation, 2001; Westwood, 2001). Miller also found that students who experienced interrupted education have limited exposure to content-specific vocabulary, experiences with how to scaffold their learning, and strategies for processing the text that they are reading.

In response to this issue, Miller (2009) conducted a study that focused on the creation of two intervention resources to support ELL students with vocabulary development. The two resources included a student dictionary and a student workbook to accompany the assigned textbook for science class. The team responsible for developing the resources included two research assistants with previous teaching experience and limited ELL knowledge.

Based on Miller's (2009) study, after the student dictionary and workbook had been created, the resources were implemented within the science curriculum for the high school students. The resources served as student support materials for one chapter of the science book curriculum. Based on the feedback from the students $(n=19)$ through a teacher-created questionnaire, the students found the dictionary and workbook to be useful. The aspects that students found helpful from the dictionary were the pronunciation guide and the illustrations to support the meaning of the words. Students felt that improvement could be added to the dictionary by including more vocabulary terms and longer definitions.

After using the intervention resources, Miller (2009) found that the students completed an end-of-chapter test where the class scored an average of $44 \%$. The end-of- 
chapter test included questions directly from the science book and no material from the intervention resource. Although the teacher stated that the students showed improvement in their scores, no specific data were provided about previous test scores.

Based on the study, the teacher reported the use of the resources as beneficial for informing teaching practices (Miller, 2009). First of all, the teacher learned that incorrect assumptions were made about the students' prior knowledge of academic vocabulary:

The assumptions weren't necessarily correct especially in the connections between words and the use of words. I just assumed kids understood because I used them and they were in the textbook and they were in our class notes and I used them every day in conversation with the students. So I assumed they knew them but they didn't. (Miller, 2009, p. 588)

The teacher's comment supports the study by Langman and Baley (2007), who found that ESL student exposure to new vocabulary does not translate to the acquisition.

Secondly, the teacher learned that changes needed to be made with the teaching pedagogy (Miller, 2009). The practice of using the intervention materials with the students highlighted the importance of focusing on student learning rather than completing curriculum content. Although the teacher found the intervention to be helpful for students and improving classroom instruction, the time commitment involved with developing future teacher-created dictionaries and workbooks was a major concern for continuing the use of the resources.

The findings from Miller's (2009) study showed that more investigation is needed to identify resources for ELL students that have led to measured gains in ELD and vocabulary acquisition. Also, more professional development is needed for teachers to support them with instructional strategies to support ELL in mainstream classrooms and 
with developing assessments that reflect the diverse learning styles and levels of all students.

Use of afterschool programs for developing literacy and language skills. Naidoo's (2009) research examined the role that afterschool programs played for high school African refugee students attending classes in an Australian public school. The research examined the barriers to education for refugee students that were created by the Australian school systems and the role that afterschool programs played to help support the inclusion of the students within the school systems. The refugee students in the study were initially from Sudan and spoke either Dinka or Nuer, which are spoken languages that do not possess written form. According to Naidoo, African students value education as an important step for attaining future employment. The English language was also identified as the most significant criteria for successful refugee resettlement.

Mainstream classes serve as an important role in helping refugee students achieve English language proficiency. However, Naidoo (2009) found several barriers that prevent refugee students from attaining this skill, including low literacy skills due to limited schooling experience, trauma from the refugee experience, and limited resources for teachers to help students adjust to their new school environments. According to Naidoo, because of these barriers, refugee students in mainstream classrooms described their experiences as stressful.

The literature on refugee students does not agree on the most efficient way for supporting them with literacy development in the classroom. However, Beck (1999) found that resources outside of formal schooling are needed to support this student 
population. To further investigate how afterschool programs can be used to help refugee students, Naidoo (2009) conducted a qualitative study using focus group interviews and semi-structured and open-ended interviews. Thirty volunteer tutors from an afterschool homework program were randomly selected for Naidoo's study. Two focus group interviews were completed during the study (Naidoo, 2009).

The results of Naidoo's (2009) research found that the afterschool homework club provided refugee students the opportunity to build cultural and social capital through learning formal English. In addition to increasing their language commodity, refugee students developed friendships with other students with similar ethnic backgrounds and tutors with refugee backgrounds.

Two areas that require further clarification from the study include specific instructional strategies and instruments used by the homework club tutors to assist students with developing English language skills and to measure improvement in the students' language proficiency. Also, the data are limited to the tutors' observations and narratives to describe the students' outcomes and does not include the students' points of view about their experiences. This study was intended to identify the most helpful instructional strategies for literacy support based on the experiences of the students.

Promising practices for refugee afterschool programs. The Bridging Refugee Youth and Children's Services (BRYCS), which is an initiative of the Migration and Refugee Services of the U.S. Conference of Catholic Bishops and the federal Office of Refugee Resettlement, provides services for refugee children to help them with the resettlement process. In 2007, the BRYCS completed a study known as Promising 
Practices to identify common factors of successful afterschool programs that serve immigrant and refugee children (Morland, 2007). The study included 60 programs across the United States and found:

Immigrant and refugee youth will benefit from community-based and afterschool programs for many of the same reasons as their nonimmigrant counterparts. However, their unique strengths and needs are important for programs to consider when targeting these youth or including them in their services. (Morland, 2007, p. 18)

The BRYCS used the positive youth development approach to creating the Promising Practices Initiative (Morland, 2007). Positive youth development incorporates a strengths-based approach to helping youth transition to become successful adults and is a promising method for supporting the unique needs of immigrant and refugee children. Four strengths were identified as significant factors that could be used for developing successful afterschool programs. First, two-parent and extended families are usually available to guide the children. Second, many immigrant children value group needs over individual needs, which is important for working collaboratively with a group and is also positively related to motivation to succeed. Third, participants learn that bilingualism is positively related to cognitive development and greater employment opportunities on a global scale (Garcia Coll \& Magnuson, 1997). Lastly, participants experience increased self-confidence and maturity. All contribute to refugee students' ability to overcome migration challenges.

Morland (2007) found that the initiative includes seven principles. The first principle includes partnering with immigrant families to provide them with community resources, such as healthcare, housing, legal assistance, and translators. The second belief is to 
engage parents and guardians in program activities like dinner celebrations and community advisory committees. The third principle includes supporting and developing bilingual staff. The fourth principle includes strengthening youths' pride in their countries of origin and identity as Americans. The fifth principle is related to helping youth develop their leadership skills. The sixth principle includes supporting the academic achievement of young people through homework clubs. The last belief is to work collaboratively with local businesses and organizations to educate the broader community about immigrant communities.

Promising Practices focuses on the strengths that refugee children possess, which counters the deficit thinking that is commonly found in the literature about refugee children (Morland, 2007). However, more information is needed in the study used to identify the seven principles that guide the Promising Practices. Also, the feedback from the refugee children's perspective on the initiative was not included in the study. A core tenant of this study is to investigate the most helpful strategies based on the perceptions of the students.

Afterschool programs and English language development. London, Gurantz, and Norman (2011) studied the role that afterschool programs play in the English language acquisition of ELLs attending the Boys and Girls Club of America program in the San Francisco Bay Area of California. The research examined the determining factors of program participation and the effect of program participation on English language proficiency gain. 
During 2008-2009, the California Department of Education (2010) reported that 24\% of the student population in the state of California identified as speaking a language other than English as their primary language (as cited in London et al., 2011). The majority of Latino students who participate in afterschool programs are ELL immigrants who come from lower income households (Kewel-Ramani, Gilbertson, Fox, \& Povasnik, 2007). Studies on afterschool programs exist for Caucasian and African American students. However, according to London et al. (2011), "Research has not fully examined the experiences of Latino youth, who may face different academic and social challenges" ( $p$. 23).

In their meta-analysis, Lauer et al. (2006) found that afterschool programs had positive effects on the reading and math achievement of low-income at-risk students. Other positive outcomes included better school attendance than nonparticipants of afterschool programs and improvement in work habits (Espino, Fabiano, \& Pearson, 2004; Huang, Kim, Marshall, \& Pérez, 2005; Lauer et al., 2006). Some evidence has also demonstrated a positive relationship between the frequency of attendance and academic gains (McComb \& Scott-Little, 2003). However, the proof of this study is difficult to duplicate due to the lack of detailed attendance records collected by afterschool programs.

In their study of the Boys and Girls Club, London et al. (2011) analyzed the data of the student participants based on four groups of English language proficiency: (a) English Only, (b) Initially Fluent, (c) Redesignated, and (d) English Learner. At the time of this study, English language proficiency was measured by the California English Language 
Development Test (CELDT) for students with a primary language other than English and was administered to students during the fall of every school year. The CELDT assessed students' English language proficiency based on four subcategories: (a) speaking, (b) listening, (c) reading, and (d) writing. The proficiency levels for each category included beginner, early intermediate, intermediate, early advanced, and advanced. To reach the level of English proficiency, the students had to score a level of intermediate or higher on each subcategory, and an overall rating of early advanced or higher. The study by London et al. (2011) included the following: $90 \%$ of participants were Latino, $65 \%$ were identified as English learners, 56\% were male, and $87 \%$ were eligible for free or reducedprice lunch.

When looking at the effect of the afterschool program on English language acquisition, London et al. (2011) measured student growth based on the ability to achieve three different milestones: (a) Annual Measurable Achievement Objective (AMAO) 1, (b) AMAO 2, and (c) Redesignated Fluent English Proficient. (RFEP). AMAO 1 and AMAO 2 are based on milestones outlined in Title III of No Child Left Behind (London et al., 2011). ELLs who participated in the afterschool program demonstrated higher achievement rates for AMAO 1 and AMAO 2 when compared to ELLs who did not participate in the afterschool program. The results found that ELLs showed gains in ELD, however, ELL participation did not affect English language proficiency levels or RFP status.

More investigation is needed to determine the instructional strategies used by the homework club tutors to help students develop their English language skills, the effect of 
homework club participation on the students' reading comprehension, and the experience and training of the tutoring staff. The feedback from ELLs on their experiences in the homework program was not included in the study.

\section{Research Method}

A documentary film served as a major component of the research design. The rationale for choosing to create a documentary film for this exploratory study was based on three main reasons: (a) documentary work possesses a history of working toward positive social change (Kemmitt, 2007); (b) the format provides subjects with the opportunity to share their perspectives about issues that directly impact them (Cravey \& Petit, 2014; Grierson, 1935; Kemmitt, 2007); and (c) documentaries serve as a creative format for contributing to scholarly work (Cole \& Knowles, 2008; Kemmitt, 2007; Petrarca \& Hughes, 2014).

Documentary work has the potential to create awareness and deeper understanding of existing social problems and the possibility to reach a wide audience (Cravey \& Petit, 2014; Grierson, 1935; Kemmitt, 2007; Petrarca \& Hughes, 2014). For instance, New Immigrants (James, Quinn, \& Saidi, 2004) illustrated the story of five individuals immigrating to the United States due to differing political, cultural, and economic reasons. In addition to experiencing the emotions conveyed by the characters, audience members gain knowledge about political, cultural, and economic factors that drive immigration patterns. The use of emotional appeal in documentary work has been associated with gaining public attention about social causes (Kemmitt, 2007). 
Video documentaries also reach audiences beyond the academic community (Cole \& Knowles, 2008; Kemmit, 2007; Petrarca \& Hughes, 2014). Public television programs such as PBS have worked in collaboration with nonprofit organizations to use documentaries as a platform for creating social awareness about common challenges faced by immigrants. Similar to the premise of documentaries, public television is grounded in educating the public about social issues. The San Francisco-based organization Active Voice worked collaboratively with James et al. (2004) to create a public campaign aimed at improving immigrants' lives.

The Virgin Appears in La Maldita Vecindad (Cravey \& Petit, 2014) is an example of a documentary film that has gained notoriety as a resource for educating the public about the immigration movement. The film depicts the lives of Mexican and Central American immigrants who live in North Carolina and directly impacted by the North American Trade Agreement. Since the film's release, The Virgin Appears has gained viewership through film festivals, immigration advocacy events, and as a high school and university curriculum resource for immigration studies (Cravey \& Petit, 2014).

Second, documentary film gives subjects a platform to voice their first-hand experiences about social issues instead of hearing about them from a third party. Subjects have the opportunity to "speak to, about, and for themselves as well as for others" (Cravey \& Petit, 2014, p. 68). Housing Problems, which was based on the experiences of residents who live in low-income British neighborhoods during the 1930s, was the first film to document the subject's point of view (Grierson, 1935). 
Third, documentaries are also gaining recognition as an alternate form of scholarly work. Petrarca and Hughes (2014) found that the process of documentary filmmaking mirrored the qualitative research methods. Further, Kemmitt (2007) contends that the combination of emotion and information through images, music, words, photos, narration, quotes, and supplemental footage conveyed through film portrays the actual truth.

Similarities between filmmaking and qualitative methods include data collection and thematic coding procedures and mindfulness of ethical consideration through every step of the study. When creating a documentary, ethical standards must also be extended to aesthetic and film editing decisions to keep the integrity of the data. In addition, the preparation of documentary footage rather than compiled text is used to communicate the study's findings.

Limitations to using this method include the number of participants willing to be interviewed on film, the primary researcher's experience with using the video-recording equipment and editing software, and the location of suitable filming environments that account for necessary lighting and audio conditions.

\section{Conceptual Framework}

The conceptual framework that was used to guide this study is based on the tenets of Gay's (2000) CRT practices. However, the inclusion of youth culture, which has been found as a critical need by educational justice scholars to expand CRT practices to be more reflective of present-day society, was also included as part of the conceptual framework (Ladson-Billings, 2014; Paris \& Alim, 2014). In addition, due to the literature 
that cites trauma as a critical issue that needs to be addressed for refugee students, TIPs implemented through the LEAD program (Miles \& Bailey-McKenna, 2016) were also used to frame the lens for this study.

\section{Culturally relative, responsive, and sustaining pedagogies. Gay's (2000) CRT}

framework evolved from the scholarship of Ladson-Billings's (1995) theory of culturally relevant pedagogy, which developed from the need to identify instructional practices that fostered the academic achievement of African American students in the classroom. This investigation identified three main paradigms that successful teachers had implemented to achieve this goal. Culturally relevant pedagogy is defined by these paradigms, which affirms and celebrate the use of students' cultural heritages and languages, addresses the need for academic excellence and high expectations for all students, and supports students with developing sociopolitical consciousness. These principles form the basis of the four categories outlined in Gay's (2002) CRT framework: (a) caring, (b) communication, (c) curriculum, and (d) pedagogy.

Culturally responsive teaching sought to address the educational needs of underachieving African American, Asian American, Latino, and Native American students. The premise of CRT is to integrate students' diverse ethnic backgrounds within the learning environment as a basis for supporting students with academic achievement (Au \& Kawakami, 1994; Foster, 1995; Gay, 2002; Kleinfeld, 1975; Ladson-Billings, 1995). According to the literature, academic attainment of ethnically diverse students improves "when they are taught through their own cultural and experiential filters" (Gay, 2002, p. 106). 
Culturally sustaining pedagogy (CSP) challenges critical researchers and practitioners to also examine how "youth culture" (Ladson-Billings, 2014), cultural and linguistic pluralism (Paris \& Alim, 2014), and sociopolitical issues can be used to shift CRT practices away from "unidirectional" correspondences to race, culture, and language. Youth-culture is not bound by unidirectional relationships to heritage. Instead, youth culture includes "shared membership, language, arts, and beliefs" (Ladson-Billings, 2014, p. 75) that can extend beyond racial heritage. Hip-hop culture is an example of youth culture studied by CSP researchers and practitioners due to its ability to connect multiple cultures through the use of African American language (AAL) that is intertwined within hip hop language and music and shared by African American, Latina/o, and Pacific Islander youth (Ladson-Billings, 2014; Paris, 2011). Paris (2011) also cited African American and Pacific Islander youth participating in Spanish language with their Latino/a peers, which is an example of the dynamic nature of youth culture.

In addition to expanding CRT practices to include youth culture, Paris and Alim (2014) assert the need to support cultural and linguistic pluralism to counter efforts that encourage monocultural practices, such as English-only mandates and the efforts by policymakers to ban ethnic studies. While the focus of this dissertation study's theoretical framework is based on Gay's (2002) CRT practices, the study also included youth culture based on the work from CSP scholars (Ladson-Billings, 2014; Paris \& Alim, 2014). The contributions from CSP scholars are necessary to continue supporting students of color as the U.S. demographics and political landscapes continue to evolve. 
Gay's culturally responsive teaching framework. To address the inequitable educational experiences for students of color, educational scholars explored the use of a CRT framework that incorporated the use of students' ethnic and cultural identities as an integral part of the educational process. The literature also refers to CRT as "culturally relative," "sensitive," "centered," "congruent," "reflective," "mediated," “contextualized,” and "synchronized” (Gay, 2010; Tillman \& Scheurich, 2013). Culturally responsive teaching is a teaching paradigm that "validates, facilitates, liberates, and empowers ethnically diverse students by simultaneously cultivating their cultural integrity, individual abilities, and academic success" (Gay, 2010, p. 46). Gay's (2002) CRT framework is based on the four elements of caring, communication, content, and pedagogy.

Caring. The first element of caring relates to the cultivation of student-teacher relationships and high expectations for all students. Relationships are strengthened when teachers focus on teaching students and not just the curriculum. Teachers must also provide students with "rigorous instruction" and "challenging curriculum" (Tillman \& Scheurich, 2013).

Valenzuela's (1999) subtractive schooling centered on the politics of caring that takes places between teachers and students, and the significant difference in how teachers and students view education. According to Valenzuela, teachers value education as the means necessary to achieve a successful life. To be successful in school, students are expected to earn good grades, score well on tests, and dress appropriately. 
On the other hand, immigrant and U.S.-born Mexican youth view educacion as a system based on reciprocal relationships with their teachers, which is aligned with the Mexican model of schooling. Consequently, the discrepancy between educators and students on the primary role of education results in "schools becoming uncaring places" (Valenzuela, 1999, p. 74) and Mexican youth transforming into "uncaring students" (p. 75). To develop a caring school system and counter deficit thinking among students of color, Valenzuela (1999) recommends developing positive reciprocal relationships with students and implementing a culturally sensitive curriculum.

Communication. The second element in Gay's (2010) CRT framework is communication. For meaningful communication to take place, Tillman and Scheurich (2013) state that students' and teachers' "languages, dialects, and cultures" (p. 439) must play a role in the context of classroom learning. For instance, culturally relevant practitioners embrace the use of students' primary languages as a valuable resource in the educational process instead of a deficit.

An example of the deficit thinking that exists with using students' home language in the classroom to learn standard English can be traced to the Ebonics Movement of the 1990s. The Ebonics Movement intended to emphasize "communication competence of West African, Caribbean, and United States slave descendants of African origin" (Debose, 2006, p. 91) and to move away from the negative stigma attached to Black English as bad English. In 1996, the Oakland School Board in California decided to recognize Ebonics as the primary language of African American students (Debose, 2006). 
Multiple media outlets and public figures erroneously interpreted the decision as enforcing the instruction of Ebonics language in the classroom. However, according to Oakland and San Francisco Board members, the purpose of the initiative was to provide English language instruction methodologies to African American students to support them with developing traditional English speaking skills. The policy was based on an existing program that was already implemented at several schools in the district and had demonstrated favorable results in English proficiency and other academic areas (Tillman \& Scheurich, 2013). In the end, the decision by the Oakland School District to use English language learning methodologies to support the students' English language proficiency was overshadowed by the conversations centered around defining Ebonics as slang rather than standard English.

In addition to being aware of the power that language plays within communication, culturally responsive practitioners must also consider the cultural differences of expected participation during conversations. For example, according to Kochman (1985), students of African American, Hawaiian, Latino/a, and Native American backgrounds prefer active communication between the speaker and the listener. This communication style includes actively listening either through body movements or vocalizations. However, most classroom environments expect students to practice passive listening while the teacher is speaking.

Curriculum. The third element in Gay's (2010) CRT framework is curriculum. Within culturally responsive practices, students are provided with a range of curriculum that is not purely centered around Eurocentric perspectives. Providing students with a 
curriculum that offers multiple perspectives encourages students to be "knowledgeable, reflective, and caring citizens" (Banks \& Banks, 1995, p. 13). Also, a multicultural curriculum promotes students not only to learn and value their own cultures but also supports them with understanding and valuing other cultures.

According to Gay (2002), CRT practitioners also integrate symbolic curriculum within classrooms. The symbolic curriculum includes the use of artifacts, illustrations, mottoes, awards, and celebrations as talking points for delivering instruction. When students of diverse ethnic backgrounds are not provided with a curriculum that reflects their diverse backgrounds, consequences such as the underrepresentation of culturally diverse students in Gifted and Talented Education Programs (GT) takes place.

Michael-Chadwell (2011) found an "underrepresentation of culturally, linguistically, ethnically diverse students" (p. 99) in GT programs, and an overrepresentation of this student population in remedial educational programs. Three primary contributors to the inequitable access to the GT programs include status quo measurements such as: (a) standardized test and IQ scores, (b) teacher deficit thinking, and (c) the ambiguous language to define gifted and talented (Michael-Chadwell, 2011). The data collected from the study by Michael-Chadwell (2011) were used to create the Chadwell transformative model for gifted program reform (CTMGPR), which was a framework that supported the "implementation of culturally relevant procedures [to benefit] the population of underrepresented, underserved gifted students" (p. 100).

According to Ladson-Billings (1995), another advantage of providing students with a culturally diverse curriculum is to support them with "develop[ing] a critical 
consciousness through which they challenge the status quo of the social order" (p. 160). However, culturally responsive practitioners continue to encounter problems with the limited number of textbooks that provide more than Eurocentric viewpoints or student novels that include characters of diverse cultural backgrounds (Tillman \& Scheurich, 2013).

Pedagogy. The fourth element in Gay's (2010) CRT framework is pedagogy. Culturally relevant practitioners tailor their instruction to fit their students' learning styles and needs. Group work, collaboration, and discussion are typical examples of teaching strategies used by teachers to meet the needs of diverse student learners. Multiple teachers found "cooperative learning strategies have proven successful in promoting the achievement of elementary students, secondary students, and college students from diverse cultural backgrounds" (Tillman \& Scheurich, 2013, p. 442). Also, culturally responsive practitioners structure instruction based on students' ethnic learning styles. Eight different components of instruction design that are modified based on ethnic learning styles include the following:

preferred content; ways of working through learning tasks; techniques for organizing and conveying ideas and thoughts; physical and social settings for task performance; structural arrangements of work, study, and performance space; perceptual stimulation for receiving, processing, and demonstrating comprehension and competence; motivations, incentives, and rewards for learning; and interpersonal interactional styles. (Gay, 2010, p. 113)

Effectively matching classroom instruction to students' learning styles can only take place through building caring relationships with students to understand their expressed needs, communicating clear and consistent high academic expectations, and providing a curriculum that mirrors the students' cultural identities. 
Literacy, English, and Academic Development Program. In addition to providing refugee students with CRT practices, Canada's Literacy, English, and Academic Development (LEAD) program incorporates TIP to address the needs of refugee students who have undergone experiences of trauma (Miles \& Bailey-McKenna, 2016). Apart from CRT and TIP, ELD is the third main component of the program. Miles and BaileyMcKenna (2016) investigated the program by using a case study approach that incorporated a hypothetical student's experiences as a participant in the LEAD program. Efforts have been made to collect quantitative data on student achievement; however, an analysis of the data has not been completed at this time. The success of the program is based on anecdotal reports from multiple stakeholders, which include the viewpoints of students, parents, and teachers.

The LEAD program's TIPs are grounded in four areas: (a) assisting students with attaining basic and socioemotional needs and mental health support, (b) implementing a "trauma-responsive framework," (c) helping students manage their emotions, and (d) using a multidisciplinary system to provide the necessary supports for students.

Created by Blaustein and Kinniburgh (2010), within the program's trauma-responsive practices are the attachment-regulation-competency (ARC) framework and bottom-up intervention. The ARC framework is based on the premise that school staff must maintain a calm state at all times since their emotions set the tone for the classroom environment (Blaustein \& Kinniburgh, 2010; Miles \& Bailey-McKenna, 2017). In addition, children who have experienced trauma are attentive to nonverbal cues that take place around them. 
The bottom-up approach is a three-stage strategy used by LEAD staff to help students regulate their emotions. Each stage must be completed before moving on to the next stage. The first stage includes helping students regulate their emotions through methods such as muscle relaxation and yoga, which is then followed by the bonding and community-building phase. Once this step is completed, school staff then focus on accessing and developing students' cognitive and metacognitive skills.

Overall, the study presented several promising strategies for supporting the unique needs of refugee students. At this time, insufficient data are available to measure the efficacy of the LEAD program. However, according to Miles and Bailey-McKenna (2016), efforts are being made to collect quantitative and qualitative data to analyze trends and determine how to improve the program to better meet the needs of students.

Conclusion. According to McBrien (2005), school systems play a significant role in supporting refugee students with successful resettlement. Due to trauma from fleeing their countries of origin, limited school experience, and language barriers, refugee students struggle with transitioning to new school environments and demonstrating progress in academic achievement. Learning challenges continue to take place when classroom teachers are not equipped with the knowledge, skills, and resources to support them with their unique learning needs. Studies on the academic achievement of refugee students cite continuous underachievement in literacy skills. The literature also underscores the need to address refugee students' experiences with trauma due to its impact on student learning. 
To address the underachievement in literacy, educational researchers and practitioners have implemented strategies to assist students with developing English language proficiency and reading comprehension. Although the literature shows promising studies in this area, there continues to be a gap in the literature with regard to the academic achievement of adolescent refugee students (ages 11-14) in reading comprehension. As the study by Miller (2009) suggests, one of the main reasons students do not understand subject content is because they do not understand the vocabulary they are presented with from textbooks or classroom lectures. Also, classroom teachers have reported not having the appropriate training or resources to support ELLs in the classroom.

Trauma-informed practices have been implemented by educational researchers and practitioners to provide the support structures needed for refugee students who have experienced trauma. Studies cite promising outcomes for TIP (Record-Lemon \& Buchanan, 2017); however, limited studies are available from the perspectives of refugee students with regard to identifying factors that provide safe learning environments.

To address these gaps in the literature, how culturally relevant teaching practices affect the experiences of adolescent refugee students who attend afterschool programs for developing literacy skills was investigated in this dissertation. Culturally responsive factors that influence students' perceptions about safety within the afterschool program environment were also examined. Since limited studies are available based on the viewpoint of the students, helpful strategies based on the perspective of the students were described in this study. 


\section{Research Questions}

1. How do culturally responsive teaching practices used in afterschool programs affect refugee students' experiences with getting support for literacy skills?

2. What culturally responsive factors influence how refugee students who have experienced trauma perceive safety within the homework club environment? 


\section{Chapter 3 \\ Research Design and Methodology}

\section{Introduction}

The purpose of this exploratory study is to examine how afterschool programs contribute to the experiences of adolescent refugee students seeking literacy development and to understand how afterschool programs are perceived as safe learning environments. First, I attempt to address this topic by sharing the research questions for the study. Second, information about the setting is provided. Third, a description of the sample group is given. Fourth, the overall approach and rationale for the documentary research design and methodology are specified. Fifth, I describe the use of a video camera as the data collection tool for the study. Sixth, validity threats and strategies to address them are given.

Studies on the academic achievement of refugee students cite continuous underachievement in literacy skills (Iaquinta, 2006; Miller, 2009; Montero et al., 2014). Due to trauma from fleeing their countries of origin; limited school experience, and language barriers, refugee students struggle with demonstrating progress in academic achievement (Ogilvie \& Fuller, 2016; Roberts \& Locke, 2001; Roxas, 2008; Szente et al., 2006; Taylor \& Sidhu, 2012). The literature also states the need to address refugee students' experiences with trauma due to its impact on student learning (Cohen et al., 2006; Record-Lemon \& Buchanan, 2017; West et al., 2014). Learning challenges continue to take place when classroom teachers are not equipped with the knowledge, skills, and resources to support them with their unique learning needs (Gebhard, 2004; Miller et al., 2005; Montero et al., 2014; Sangster, 2001; Szente et al., 2006). The 
literature shows promising studies to assist refugee students in developing their literacy skills. However, limited studies are available with regard to the academic achievement of adolescent refugee students (ages 12-17). Trauma-informed practices have been implemented to provide support for refugee students who have experienced trauma. However, limited studies are available from the perspectives of students with regard to identifying factors that provide safe learning environments.

A major component of this study involves the use of a documentary film to capture the students' perspectives. The findings from the study will be used to inform educators, researchers, and policymakers with additional support structures to meet the unique needs of refugee students. The conceptual framework that was used to guide this study is based on the tenets of Gay's (2000) CRT practices. The inclusion of youth culture, which has been found as a critical need by educational justice scholars to expand CRT practices to be more reflective of present-day society, was also included as part of the conceptual framework. In addition, due to the literature that cites trauma as a critical issue that needs to be addressed for refugee students, TIPs implemented through the LEAD program (Miles \& Bailey-McKenna, 2016) were used to frame the lens for this study.

\section{Research Questions}

RQ 1 . How do culturally responsive teaching practices used in afterschool programs affect refugee students' experiences with getting literacy support?

RQ 2. What culturally responsive factors influence how refugee students who have experienced trauma perceive safety within the afterschool program environment? 


\section{Description of the Setting}

Three organizations agreed to participate in the study: (a) Sacred Heart Education Center (SHEC), (b) Eritrean Community Center (ECC), and (c) Catholic Charities of Santa Clara County (CCSCC). All three organizations are located in the San Francisco Bay Area.

Sacred Heart Education Center. The SHEC Homework and English Programs provides homework assistance to students in grades kindergarten through high school and supports students in the areas of math, reading, and writing. Students self-select to attend SHEC and are not required by school administrators to enroll in a tutorial program. SHEC uses volunteer tutors from nearby universities and high schools to work with students either through small group or one-on-one assistance.

The SHEC program coordinator recruits students at the nearby parish by advertising free homework assistance and a safe quiet learning environment. The program is open 4 days a week during the school year and offers a free 10-week summer school program. Although SHEC is located within the Sacred Heart Nativity School campus building, students from Sacred Heart Nativity School do not attend SHEC since the school has its own afterschool program.

Sacred Heart Education Center students attend public and charter schools in the adjacent neighborhood and qualify for free and reduced lunch. Spanish is identified as the primary language for the attendees. The program coordinator and assistant program coordinator were identified as bilingual in Spanish and English, while the majority of volunteer tutors only spoke English. 
The SHEC is funded primarily through donations from the nearby Catholic parish and grants from local and national Catholic organizations. A neighborhood restaurant provides free snacks for students, while local schools donate school supplies and books on an annual basis. The pastor from the parish is the primary decision-maker on financial decisions and facilities management. The SHEC program coordinator is responsible for student enrollment, tutor recruitment and scheduling, and student instruction. The assistant coordinator prepares the classroom, organizes supplies, coordinates tutoring support for students, and provides student instruction.

Eritrean Community Center. The ECC provides academic support and socialization opportunities for students in middle school and high school who are identified as refugees from Africa. Students self-select to attend ECC and are not required by school administrators to enroll in a tutorial program. Tutoring services are provided by volunteer tutors from nearby universities, while funding for tutorial resources are primarily from donations. Tutors help students in several different subject areas such as math and English and also provide computer assistance. The program director coordinates tutorial services between students and tutors and plans weekly socialization events intended to celebrate Eritrean culture and to empower and educate students. The program director recruits students through websites, social media, and networking events.

Tigrinya is the primary language spoken by the students. The program director and tutor who participated in the study identified as speaking Tigrinya and English. Information was not collected on the language backgrounds of other ECC tutors. Tutorial services are provided approximately three to four times per week and are based on the 
needs of the students and availability of tutors. Tutorial services are provided at the ECC building.

\section{Catholic Charities of Santa Clara County. Catholic Charities of Santa Clara} County is an organization governed by the United States Council of Catholic Bishops. Catholic Charities of Santa Clara County supports refugee foster youth by identifying adult sponsors for youth before relocating to the United States and enrolling youth into the U.S. school system. The majority of refugee youth who receive services from CCSCC migrated from Eritrea, the Democratic Republic of the Congo, Democratic People's Republic of Korea, and Central America. In addition to providing foster care services, CCSCC offers independent living skills workshops and partners youth with contracted tutoring centers. Students self-select to receive tutorial services through CCSCC and are not required by school administrators to enroll in a tutorial program.

Tutors are employed through the tutoring centers, not CCSCC. The education case manager communicates the students' academic needs and preferences to the tutoring centers. Services are provided to CCSCC students based on the availability of tutors throughout the week. The CCSCC building has a designated classroom for student use; however, it is unclear if students receive services at the CCSCC or tutoring center locations. Due to the foster youths' diverse cultural backgrounds, it is unclear what languages are predominantly spoken by the students. All tutors are required to have a Master's degree in the subject area they are tutoring in and be fluent in English. However, it is unclear what other languages are mainly spoken by the tutors. 


\section{Description of the Sample}

Student participants were selected and introduced to me by the program directors and coordinators who were knowledgeable about the student population and the topic for this documentary study. The student interviewees met the definition of refugee used for the study and identified as receiving support for their literacy skills. For this study, the term refugee refers to: (a) the definition outlined by the 1951 Refugee Convention and 1967 Protocol, which includes individuals fleeing their countries due to displacement from war or the fear of being targeted as a victim of violence because of religion, race, gender, political affiliation, or sexual orientation; and (b) individuals who flee their countries from urgent humanitarian crises due to extreme poverty, fear of violence, and human traffickers.

After sharing the primary researcher's professional and educational background with the students and the purpose of the study and interviews, the students agreed to participate in the study. The SHEC program coordinator also introduced the primary researcher to the students' parents, who gave consent for their children to participate in the study. Since the ECC student was 18 years old at the time of filming, parental consent was not required. One former tutoring student from CCSCC who was over 18 at the time of filming agreed to participate in the film to share past challenges from high school and how experiences from the homework program has impacted her adult life. Table 1 shows the background information of the student participants. 
Table 1

Documentary Student Participants

\begin{tabular}{lllll}
\hline Name & $\begin{array}{l}\text { Primary } \\
\text { Language }\end{array}$ & Grade Level & $\begin{array}{l}\text { Length of Time as Homework } \\
\text { Club Participant }\end{array}$ & Organization \\
\hline Anna & Spanish & Middle School & 2 years & SHEC \\
Anthony & Spanish & High School & 10 years & SHEC \\
Elena & Tigrinya & High School & 2 years & ECC \\
Jennifer & Spanish & Middle School & 7 years & SHEC \\
Matt & Spanish & High School & 7 years & SHEC \\
\hline
\end{tabular}

Note. $n=5$

Other participants interviewed for this study included program directors and coordinators, tutors, and the Director of Civic Engagement for an immigrant advocacy organization. The initial contact with $\mathrm{CCSCC}$ was completed through an email inquiry to participate in the project, which led to agreement from the independent skills and education services coordinator to complete the video interviews. Although several adolescent youth and guardians were asked to participate in the film, the adult former student was the only individual who responded with interest.

The ECC program manager was introduced to the primary researcher through a foster refugee youth and adult sponsor who originally agreed to participate in the film but later chose not to participate in the project. Four students from ECC were present during the day of filming the interviews; however, only one student agreed to continue with the interviews on camera.

The SHEC program manager serves as a substitute teacher in the primary researcher's school district and became interested in participating in the research project after hearing about the documentary topic. Five SHEC students originally agreed to complete the interviews; however, four students chose to continue with the interviews through the 
duration of the project. There were no parents who agreed to be interviewed on film. The initial contact with the Services, Immigrant Rights, Education Services (SIREN) was completed through email inquiry. Table 2 provides background information about other participants from the study.

\section{Methods}

A documentary film was selected as the research methodology for this exploratory study. The documentary format was selected due to four main reasons. First, the use of narrative storytelling coupled with documentary film provides rich descriptive data that is necessary to convey the educational and emotional experiences of refugee students from their perspectives (Cravey \& Petit, 2014; Grierson, 1935; Kemmitt, 2007; Merriam \& Tisdell, 2016). Second, the documentary is an effective medium for drawing public attention to and educating the public about the unique needs of refugee students and promising strategies to support their academic development (Grierson, 1935; Kemmitt, 2007). Third, the video documentary helps the audience visualize the safety issues that refugee students undergo while navigating through their educational experiences. Fourth, the documentary format has the potential to broadly share the exploratory findings with an audience that extends beyond academic researchers, such as education professionals, policy decision makers, nonprofit organizations, and schools (Kemmit, 2007; Cole \& Knowles, 2008; Petrarca \& Hughes, 2014). 
Table 2

Other Documentary Participants

\begin{tabular}{|c|c|c|c|}
\hline Name & Role & Responsibilities & Organization \\
\hline Betsy & Program coordinator & $\begin{array}{l}\text { Citizenship and English } \\
\text { instruction for parents, } \\
\text { homework club student } \\
\text { instruction, student and tutor } \\
\text { recruitment and supervision }\end{array}$ & SHEC \\
\hline Vanessa & $\begin{array}{l}\text { Assistant program } \\
\text { coordinator and tutor }\end{array}$ & $\begin{array}{l}\text { Homework club student } \\
\text { instruction and student and tutor } \\
\text { supervision }\end{array}$ & SHEC \\
\hline Spencer & Volunteer tutor & $\begin{array}{l}\text { Homework club student } \\
\text { instruction }\end{array}$ & SHEC \\
\hline Tay & Volunteer tutor & $\begin{array}{l}\text { Homework club student } \\
\text { instruction }\end{array}$ & SHEC \\
\hline Jeremy & $\begin{array}{l}\text { Director of civic } \\
\text { engagement }\end{array}$ & $\begin{array}{l}\text { Advocacy efforts for } \\
\text { immigration rights and laws, } \\
\text { voter registration, census } \\
\text { outreach and education }\end{array}$ & $\begin{array}{l}\text { Services, Immigrant } \\
\text { Rights, and } \\
\text { Education Network } \\
\text { (SIREN) }\end{array}$ \\
\hline Girmay & Program director & $\begin{array}{l}\text { Student and tutor recruitment } \\
\text { and supervision, social events } \\
\text { and workshop coordinator }\end{array}$ & ECC \\
\hline Hana & Volunteer tutor & $\begin{array}{l}\text { Homework club student } \\
\text { instruction }\end{array}$ & ECC \\
\hline Karen & $\begin{array}{l}\text { Former homework } \\
\text { club student }\end{array}$ & $\begin{array}{l}\text { Received support for English } \\
\text { language and literacy support }\end{array}$ & CCSCC \\
\hline Liz & $\begin{array}{l}\text { Independent living } \\
\text { skills and education } \\
\text { coordinator }\end{array}$ & $\begin{array}{l}\text { Workshop coordinator, school } \\
\text { enrollment, tutoring services } \\
\text { coordinator, student instruction }\end{array}$ & CCSCC \\
\hline
\end{tabular}


Data collection process. The observation instrument, a high definition (HD) video camera, was used to record student interviews, information about the homework programs' physical setting, participant activities and interactions, instructional focus, and educational resources. Other interview participants included tutors, program directors and coordinators, an immigrant advocacy representative, and former student. The interview questions, which were aligned to the research questions, consisted of both highly structured and semi-structured questions (see Appendix A). To integrate Gay’s (2010) CRT framework into the instrument, participant race/ethnicity, language(s) spoken at home/homework program, availability/use of multicultural curriculum, and tutor-student relationship building were included as part of the interview process and included in the documentary editing script. Student responses on perceptions about safety in their learning environments were also included. Probing questions developed organically based on the direction and details of the interviewees' responses.

Interview process. Building relationships with the participants was the first step taken before conducting the interviews. Developing this aspect resulted in a more comfortable interview process and encouraged the participant to elaborate on their responses. Immediately before the interviews, the respondents were provided with copies of the interview questions, an opportunity to select which items they felt comfortable answering, and assistance from a translator if needed. Student participants were given the opportunity to ask clarifying questions about the interview questions and practice their responses with other participants or tutors before starting the filming process. 
Several steps were also taken to help the students feel more comfortable with being recorded with a video camera during the interview process. For instance, student participants were given the option to have either their faces or hands recorded during the interviews and opportunities immediately after the interviews to review the footage and determine if the footage accurately depicted their intended responses and if they wanted to add or delete information. Another critical aspect that helped build relationships with the students was the invitation for them to learn about the filming equipment and participate in the filming set-up process.

\section{Data Analysis}

Thematic analysis was used to analyze the students' responses from the video interviews. This strategy was helpful for categorizing students' points of view on: (a) how CRT practices affect their experiences at the afterschool program for developing literacy skills, and (b) what culturally responsive factors influence how refugee students who have experienced trauma perceive safety within the homework club environment.

Participant responses were transcribed and examined to see if they relate to the four elements from the CRT framework: (a) caring (CA), (b) communication (CO), (c) curriculum (CU), and (d) pedagogy (PD). Evidence about youth culture (YC) and perceptions about safety (S) were also collected to determine how these aspects affected students' learning experiences. The participants' responses were assigned codes and recorded into an Excel spreadsheet. As more data were collected, the codes were further developed to identify recurring themes that became part of the documentary film. 


\section{Documentary Production Process}

The documentary production process involved three stages: (a) preproduction, (b) production, and (c) postproduction.

Preproduction. The preproduction stage included a review of the literature, development of research questions, and identification of possible locations and interviewees as the focus of the documentary (Chapters 1, 2 and 3 of the dissertation). As a novice film maker, the primary researcher met with the dissertation chairperson and online film editor to learn how to use the video camera and microphone, frame interviewees and stage the background scenes, and adjust the lighting when filming. The online film editor provided the primary researcher with a tutorial on how to use Adobe Premiere Pro, which is the editing program for the documentary. The filming and editing equipment were provided by San José State University's EdD program and accessible for the entire duration of the project.

Production. This production stage included setting up the video camera and sound equipment and filming interviews, participant interactions, and the classroom learning environment.

Set-up. The set-up process included selecting a location with appropriate lighting, setting up the video camera on the tripod, preparing the microphone and testing the sound quality, and framing the interviewees within the camera lens. Since all student participants requested to film their interviews indoors at the homework club, limited locations were available for filming. Because of this, a staging process that included re- 
arranging furniture and adding props was also completed to ensure that the background scenery was aesthetically pleasing.

Interviews, participant interactions, and the learning environment. During the filming process, several adjustments were made based on interviewee preferences. For instance, all student participants requested that they complete the interview with another homework club youth participant sitting next to them. In addition, one student requested not to record her face on camera for the entirety of the film. To accommodate this request, only her hands were filmed during the interviews and all additional footage was filmed with her back to the camera. Similar accommodations were also made for another student, who after several months of completing interviews with her face to the camera, requested not to have her face recorded over the last few months of completing the documentary. However, the student did give permission to include the use of previously recorded footage for the film and to record the remainder of the interviews with the camera angled towards her hands.

When filming participant interactions and the classroom learning environment, special attention was given to angling the video camera to limit recording other students and adults who did not participate in the interviews and to minimize any personal student information that could be recorded through the microphones.

Postproduction. The postproduction process consisted of analyzing and coding the interviewee responses, editing the footage based on the editing script, including visuals (b-roll) and narration, and adding subtitles. 
Analyzing and coding interviewee responses. During this stage of the documentary process, interviews and other footage was coded and organized into an editing script. The process for coding the interviews included transcribing the footage, coding the data from the transcripts, and then entering data into a master spreadsheet that was categorized initially by the following topics: Caring, Curriculum, Pedagogy, Communication, Youth Culture, and Safety and by the name of the subject interviewed. Themes were identified through reviewing the data from the master spreadsheet and reviewing the footage to observe participant interactions and the classroom environment.

Editing the footage. After themes were identified, a documentary script was created to plan the narrative storyline for each student participant. The storyline incorporated the types of support provided to each student and how the students' benefitted academically and personally from attending the homework club. The documentary script included background information about each organization, student and tutor recruitment efforts, narrative storyline for each student, and students' definition of safe learning environments. While individual challenges within the school setting were illustrated in the students' narrative storylines, the end of the script was organized to communicate systemic issues that contributed to the students' experiences.

After completing the editing script, clips of the raw footage were imported into Adobe Premiere Pro software and then organized into sequences based on the editing script. Visuals (b-roll) were added to the footage to help the audience visualize the message that was being conveyed by the speaker and during instances where the subjects did not want their faces on camera. The last two steps included adding narration and sub- 
titles. Narration was intended to add information that was not included in the edited footage and provide transitions from one subject to another. Subtitles were included to help clarify the message conveyed by the speaker. Careful attention was also given to blur the faces of students in close camera range who were not part of the documentary study. During the postproduction process, frequent check-ins with my dissertation advisor were completed to get feedback on my progression with editing the film. I was also provided with ongoing support from my online editor to assist with technical issues I encountered with using the Adobe Premiere Pro software. After successful completion of the postproduction stage, the documentary was deemed ready for viewing and distribution to relevant audiences.

\section{Validity Threats}

Research bias, researcher influence, and peer influence are three types of validity threats for this exploratory study. Strategies to address these issues included collection of rich data and respondent validation. Rich data were collected from student respondents at SHEC through multiple interviews and observations. Students also had opportunities to view recorded footage immediately after their interviews and provide feedback. Although the interviews from ECC and CCSCC were limited to one or two interviews, participants were also given a chance to view and provide feedback immediately after their interviews. Providing respondents with the opportunity to select the interview questions, avoiding leading questions during the interview process, and inviting students to be part of the documentary filming process were strategies to limit researcher influence. To address peer influence during the research process, SHEC students were interviewed in a 
variety of settings: partnered with different peers during interview sessions and in some instances completed solo interviews. Although efforts were made to limit researcher and peer influence within the data collection process, the possibility of researcher and peer influence cannot be eliminated from the participant responses. Due to the limited number of interviews completed with ECC, there was no opportunity to interview the participant in an individual interview setting.

\section{Potential Bias and Limitations}

Potential bias in this study is based on assumptions found in the literature on the educational experiences of refugee students. First of all, studies show that refugee students continue to demonstrate underachievement in reading comprehension, classroom teachers are not equipped to support the needs of the students, and that afterschool programs and tutoring support are solutions to address these issues (Neuman, 2010; Sung \& Chang, 2008; Tillman \& Scheurich, 2013). Secondly, the literature also finds that refugee students have underlying experiences with trauma that are negatively impacting their learning (Ogilvie \& Fuller, 2016; Roxas, 2011; Szente et al., 2006; Taylor \& Sidhu, 2012).

Four main limitations were identified during this exploratory study. The first limitation included the small sample size of refugee students with parental consent to participate in the study. The second limitation included the lack of formal training in CRT and LEAD practices provided to the afterschool program tutors. Tutors from SHEC and ECC were familiar with CRT and TIP, but no formal training was provided to them either before or during the time of the study. SHEC and ECC tutors were not familiar 
with the LEAD program. The researcher was unable to determine if tutors contracted with CCSCC received CRT or TIP training, or if there was familiarity with the LEAD program. The third limitation was the limited number of afterschool organizations that provide academic support for this student population. Lastly, since the researcher only speaks English, Ilocano, and Hawaiian pidgin, assistance from translators and tutors were required to clarify interview questions for student participants and when communicating with parents.

These limitations were addressed through collection of rich data and using responded validation when interpreting the interviewees' responses. In addition, the investigation of the student participants' experiences was based on exposure to CRT and LEAD elements that were organically present during tutoring support. The organizations participating in the study were not required to show evidence of formal training in these areas.

\section{Role of Researcher}

The primary researcher for this study served as a middle school English language arts classroom teacher for 10 years and is currently the vice principal of academics at a Catholic elementary school (Grades TK-8). The researcher is not employed or in any way affiliated with the organizations that were used in the study. The role of the researcher is to conduct exploratory research through the use of documentary work to bring attention to how afterschool programs can be used as an outside resource to meet the unique needs of refugee students; bring attention to the necessity of addressing refugee students as a separate group from immigrant students; and inform educational professionals about 
effective strategies for supporting refugee students with developing their literacy skills and cultivating safe learning environments.

\section{Ethical Considerations}

Several efforts were made to help build trusting relationships with the students over the course of the documentary research study. The SHEC homework club coordinator helped the primary researcher gain credibility through introductions to the SHEC community. The researcher also completed bimonthly visits with the students in hopes of helping them become more familiar and comfortable with the researcher's presence. The researcher showed interest in their hobbies and homework progress during casual conversations, eating and conversing with them during snack time, and by sharing professional and personal schooling experiences with the students. Attending the Services, Immigrant Rights, and Education Network (SIREN) banquet with the SHEC homework club coordinator also showed the parents the researcher's interest in supporting immigrant and refugee communities.

The ECC homework club director also helped the researcher gain credibility through introductions to the ECC community. To build a trusting relationship with the ECC student participant, the researcher attended an ECC social event to interact with the student by learning about Eritrean food and music and socializing with the elders from the community. The CCSCC education coordinator was instrumental in helping the researcher build trust with the former tutoring participant before filming. Researcher and CCSCC education coordinator discussions were centered around how participation in the 
interviews could benefit other refugee youth who may be experiencing difficulties in their schooling and the participant's educational and career goals.

Media release forms with parental consent and minor assent were collected. The interview protocol includes a scripted statement that explained the purpose of the interview and how the data obtained from the interviews would be used. A translation of the interview protocol was provided for students and parents. The researcher's affiliation with the afterschool programs and the participants were limited to this study. There were no potential conflicts of interest.

\section{Conclusion}

Although efforts are being made to understand how to best support refugee students in the U.S. school system, students continue to struggle with literacy skills, which are critical elements for academic achievement. This documentary study explored the experiences of adolescent refugee students who used afterschool programs as an additional resource for helping develop literacy skills and their perceptions about safety within the homework club environment. Gay's (2010) CRT framework and aspects of the LEAD program's TIP were used as the lens to help guide the design, data collection, and data analysis for the study. 


\section{Chapter 4 \\ Summary of Findings}

\section{Introduction}

The purpose of the exploratory study was to understand the experiences of adolescent refugee students who attend afterschool programs for literacy support. Using a documentary research framework, student participants shared their experiences on these two areas:

RQ 1. How do culturally responsive teaching practices used in afterschool programs affect refugee students' experiences with getting literacy support?

RQ 2. What culturally responsive factors influence how refugee students who have experienced trauma perceive safety within the afterschool program environment?

\section{Creating Safe Learning Spaces in Turbulent Times}

The findings from the study are illustrated in the documentary Creating Safe Learning Spaces in Turbulent Times. The documentary consists of four segments: (a) organizational background for each homework club location, (b) student narratives, (c) underlying social issues that affect students' learning experiences, and (d) the participants' definition of safe learning environments. In an effort to share the findings from the study while keeping the audience engaged, several of the student responses shared in the film were representative of responses across all participants.

Research Question 1: Experiences with literacy support. The first research question was: How do culturally responsive teaching practices used in afterschool programs affect refugee students' experiences with getting literacy support? In response to this question, several main themes emerged. First, caring tutors were identified across 
all participants as a major contributing factor to their positive experiences at the afterschool programs. When asked about what she liked best about attending the afterschool program, Anna provided the following response:

Everybody there is good friends with you. There are tutors, like people who help. They are helpful like when you are nervous they like to help you to feel more better. The first time I go there, I was so nervous because of how I look, or what I do, or if I have friends or not, so like they help you to feel your feelings. Like [the tutor] Vanessa, she always help me when I feel sad. She helps me always with that.

Second, use of the student's primary language while providing tutoring support was helpful for improving comprehension and vocabulary acquisition. Socializing with other youth that spoke the same primary language and shared the same culture were other positive aspects that emerged from the documentary research. Elena described how speaking Tigrinya with other members was what she liked best about attending the afterschool program when she stated, "I like to meet people with the same culture. You speak the same language. You share ideas what you want with your language. I like the best thing is to share ideas with different people by your language."

Third, providing students with individualized explicit direct instruction was the instructional method preferred across all participants and demonstrated among all tutors. Jennifer described the type of instruction that she and the other participants found most helpful:

They show me how to do my problems step by step. She [the tutor Vanessa] gives me examples. And then from those examples I try to do them, and I get it. It's really easy. The teacher [at school] gives us really hard explanations. And she [the tutor Vanessa] gives really easy ones. 
In addition to supporting his understanding of the content, Matt explained another benefit of receiving individualized explicit direct instruction:

They lead me through the subject, and we don't move onto the next question until I get the answer right, so that helps me. That motivates me to do better because sometimes I've been stuck on the same questions for like an hour, and I don't do it. Then, I get a bad grade for it. But the homework center really motivates me.

A characteristic of youth culture found across all participants was the routine use of technology for either academic or personal reasons. Other insights that youth shared during the interviews included limited support from classroom teachers and the tendency to avoid subjects and assignments that challenged their English writing skills.

The majority of the assignments completed at the homework programs were based on coursework assigned by the classroom teacher. There was no evidence of culturally responsive curriculum materials provided to the students as homework assignments. However, SHEC provided students with novels and reference materials in Spanish.

Research Question 2: Perceptions about safety. One common theme emerged in response to the question, "What culturally responsive factors influence how refugee students who have experienced trauma perceive safety within the afterschool program environment?" Similar to students' experiences with receiving literacy support, caring tutors played the most significant role in helping students feel safe in their learning environments.

When asked to describe how the afterschool program provided a safe learning environment, Jennifer provided the following response: 
It's really safe because they make sure you're in the right place. They make sure you're in class, that you're not doing something wrong. And they keep an eye on you in case something's wrong with you. If they see like you're sad or upset or mad, they tell you, "What's wrong?" And they help you with it.

Student participants' definition of safety ranged from secure buildings, classrooms located away from street access, locked classroom doors, adult supervision, security personnel, and small classroom settings. Anthony's definition of safety focused on secure buildings. He stated, "This homework club is safe for learning because we are all in one small room. And the whole school is locked. They have the doors locked so like unknown people don't get in.” Matt expressed concern regarding his perception about increasing racism towards Latino communities and described how the homework club was a safe learning environment due to the familiar small group environment:

The homework club is just full of friendly people and full of people that I know and people that aren't mean and that aren't disrespectful. We all respect each other in the homework center. It's a small group of people, so it's actually more comfortable.

Footage not found in the documentary. One critical aspect of the study that was not included in the documentary was the participation of the SHEC students in the filming process. During the first few filming visits, the researcher was solely responsible for the set-up and filming process. In an attempt to develop a comfortable dialogue with the participants, students were given opportunities to participate, which ultimately led to established routines for the filming visits. For instance, Anthony participated by moving the equipment to different filming locations. With past experience creating video blogs and filming documentaries, Matt assisted with setting up the tripod, providing feedback on camera angles, and recording several shots of b-roll. Anna and Jennifer also frequently 
shared their opinions on camera angles; however, Jennifer became increasingly active with helping the other students practice their responses for the interview questions, setting up the clip-on microphones, and selecting background settings. The increased participation in the set-up and filming process was ultimately followed by more detailed responses when answering the interview questions and a relaxed interview environment.

Other video footage that was not incorporated into the documentary included an interview with a volunteer tutor from the ECC. Hannah from ECC described language barriers as the most common obstacle for students. She explained her process for helping students with reading comprehension, which included identifying main ideas from long reading passages through segmenting the content into smaller sections and providing explanations for unfamiliar words. Hannah also described how she provided transportation for students to the tutoring center as an attempt to help students feel safe and comfortable with her and the tutoring environment. Although Hannah's interview directly addressed the questions, poor audio recording from the interview could not be adjusted and the decision was made not to include the footage. 


\section{Chapter 5 \\ Discussion}

\section{Introduction}

Through the process of completing the documentary, adolescent refugee youth were given an opportunity to describe their experiences with attending afterschool homework programs for literacy support and to share their perceptions surrounding safe learning environments. The majority of the documentary footage was based on the narratives of four students from the SHEC. Filming began with the SHEC students during Fall 2017. During Fall 2018, the study was expanded to include interviews from one participant who was receiving tutorial services from the ECC and one former student who received services through CCSCC.

\section{Summary of Findings}

The findings from the exploratory study were illustrated through the video documentary entitled Creating Safe Learning Spaces in Turbulent Times. The footage from participant interviews, student interactions, classroom learning environments, associated b-roll, and documentary narration all contributed to addressing the Research Questions for the study:

RQ 1. How do culturally responsive teaching practices used in afterschool programs affect refugee students' experiences with getting literacy support?

RQ 2. What culturally responsive factors influence how refugee students who have experienced trauma perceive safety within the afterschool program environment? 
Summary of RQ1 findings. The first research question was: How do culturally responsive teaching practices used in afterschool programs affect refugee students' experiences with getting literacy support? When examining the students' responses related to this question, the CRT practices that were identified as the most helpful by students included: (a) the use of their primary language when receiving homework support, (b) caring tutors who provided individualized attention, and (c) explicit step-bystep instruction. Access to technology was also identified by youth as a critical component of their experience due to its necessity as a communication tool, resource for completing assignments, and strategy for improving English skills.

In addition to identifying the most helpful strategies and resources, participants from the study described how the afterschool programs helped improve their grades. Other positive outcomes included an increase in self-confidence, motivation to complete homework, and opportunities to socialize with peers who shared similar cultural backgrounds and primary languages. Karen, the former tutoring student from CCSCC, shared how tutoring support improved her English language skills and has helped with her current success in college.

The findings from the documentary study are consistent with the literature surrounding CRT practices, which emphasizes teaching students and not just the curriculum (Au \& Kawakami, 1994; Gay 2010, 2002; Ladson-Billings 1995, 1994; Valenzuela, 1999). According to Valenzuela (1999), students view positive reciprocal relationships with their teachers as a critical aspect of their educational experience, which is aligned with the Mexican model of schooling. First, the caring behaviors exhibited by 
afterschool program staff and volunteer tutors highly contributed to the students' positive experiences. The SHEC participants identified the tutor Vanessa as the tutor they work with most because she was "helpful," "nice," "funny," and knowledgeable. Anna described how Vanessa provided her with emotional support by spending time to converse about her daily experiences and with processing her feelings. Karen from CCSCC stated that her favorite memory about her tutor included bringing Karen food from her home country during their tutoring sessions.

In addition to developing positive relationships with students, another tenant of CRT practices includes possessing and communicating high expectations for students (Au \& Kawakami, 1994; Foster, 1995; Gay, 2010, 2002; Ladson-Billings, 1995, 1994). Although not directly shared by student participants, interviews with afterschool program adult staff showed that they communicated high expectations for their students, through discussions about maintaining high grades and enrolling in college and planning workshops to help empower students. Afterschool program adult staff also spoke about ongoing efforts to partner students with tutors that could help them in subject areas and levels that were beyond the teaching capacity of the current tutors and acquiring necessary learning and technology resources for students to complete their homework. Betsy coordinated efforts with nearby local restaurants to provide healthy snacks for students when at the homework club, while Girmay coordinated weekly socialization events that were centered around workshops to help empower students. In addition to helping students attain tutoring support from contracted tutoring centers, Liz actively 
participated in helping youth attain educational services, such as an individualized learning plan (IEP) and 504 Plan.

Second, the use of students' primary language to help them understand the subject content is another CRT characteristic (Au \& Kawakami, 1994; Foster, 1995; Gay, 2010, 2002; Kleinfeld, 1975; Ladson-Billings, 1995, 1994). Anna, whose primary language is Spanish, described how she could identify the words that non-Spanish speaking tutors were using during instruction, but she could not understand the message that they were trying to convey. Jennifer shared how the use of Spanish at the homework helped to improve her Spanish skills, while Elena explained how her favorite aspect about attending the tutorial center was the opportunity for her to speak Tigrinya with fellow Eritrean members.

Third, the use of a pedagogical approach that is most helpful for students from similar cultural backgrounds is identified as a CRT practice (Gay, 2010). Within the context of refugee youth attending afterschool programs, student participants identified the following instructional strategies as the most helpful: (a) "step-by-step" approach that incorporated "a lot of examples," (b) "explanations that were easy to understand," and (c) individualized instruction. All three instructional approaches were observed while tutors worked with students when completing homework.

According to CSP practitioners, youth culture extends beyond racial heritage and instead is defined as "shared membership, language, arts, and beliefs" (Ladson-Billings, 2014, p. 75; Paris \& Alim, 2014). Technology was embedded as part of the students' youth culture, which was captured in the b-roll segments and through student interviews. 
In addition to using the computer and internet resources provided by the homework clubs to complete their assignments, the majority of students depended on the school's online gradebook system to determine assignment grades and academic progress. Students were also routinely observed using their personal cellular phones for completing calculator functions, texting with friends, playing video games, and listening to music. Karen described how audio books were helpful for practicing English fluency, while Matt discussed his interests in creating documentary films and video blogs. At the end of my interview with Elena, she described her desire to improve her technology skills since it is such an important part of U.S. culture.

There was no evidence of culturally relevant curriculum materials when students completed the homework assignments assigned by their classroom teachers. However, Spanish versions of novels and reference materials were available for student use at SHEC.

Summary of RQ2 findings. The second research question was: What culturally responsive factors influence how refugee students who have experienced trauma perceive safety within the afterschool program environment? When reviewing the students' descriptions of this research question, caring relationships with trusted adults and fellow classmates played a significant role in how students described a safe learning environment. School buildings and classrooms with locked doors, learning spaces located inside of secure buildings, transportation services from students' homes or schools to the afterschool programs, and security surveillance personnel were other items identified by students that helped them feel safe. 
The findings from the study are consistent with the literature surrounding traumainformed practices, which identifies caring and relationships as important support structures for adolescent youth who have experienced trauma (Miles \& Bailey-McKenna, 2016).

\section{Framing Educational and Societal Issues}

Program managers and coordinators, tutors, and a representative from an immigrant advocacy organization provided other important information related to the research topic, such as common academic challenges facing youth and economic and immigration societal issues that impact the students' learning experiences. Language barriers were identified as the most significant challenge facing refugee students, which is consistent with the literature surrounding this student population (Ogilvie \& Fuller, 2016; Roberts \& Locke, 2001; Szente et al., 2006; Taylor \& Sidhu, 2012). The afterschool programs partnered students who spoke Spanish as their primary language with Spanish-speaking tutors; however, it was more challenging to find tutors to partner with students who spoke other languages, such as Tigrinya.

Program leaders also shared issues with finding tutors who had training and experience with teaching ELLs, reading comprehension skills, higher level math and science content, and TIP.

\section{Implications for Practice}

Student participants from the documentary research identify caring relationships with tutors, use of primary language, explicit direct instruction, and social-emotional support as critical components of their positive experiences from the afterschool programs. 
Although the findings are limited to the student participants from the documentary research, educators and administrators should investigate the advantages of adopting or strengthening these practices as part of the support structures for refugee youth.

One program to consider investigating is the LEAD program (Miles \& BaileyMcKenna, 2017), which combines the use of culturally relevant and trauma-informed teaching practices. First, students are provided with ELD that uses explicit individualized direct instruction and culturally relevant teaching practices. English language development support is communicated in a manner that values the use of students' primary languages to learn English and the use of curriculum that reflects the students' cultures. English language development practitioners also create purposeful opportunities for students to practice their English skills in both academic and social settings and are attentive to helping students feel included within the school and community environments.

Second, students are provided with coping strategies to address issues of trauma. Students are provided with relaxation techniques that incorporate controlled breathing and physical movements, such as yoga and tai-chi to help students manage their emotional states. When students have regulated their emotions, LEAD program practitioners create purposeful opportunities for the class to build relationships. After these two aspects are addressed, students transition to activities to support academic development.

According to Miles and Bailey-McKenna (2017), TIPs are not meant to be used as treatment for trauma but instead are strategies to support students with coping strategies 
from traumatic experiences and for reducing environmental factors in the school setting that may be traumatizing for students. In addition to receiving trauma-informed professional development, LEAD program teachers partner with medical specialists with whom they can refer students to receive proper mental health services.

Program leaders communicated occasional challenges with finding tutors who possessed the experience and training necessary to support refugee youth. Although the findings are limited to the program leaders who participated in the documentary research, educators and administrators at both school site and afterschool program who provide tutoring assistance should investigate the advantages of establishing tutor training protocols to provide basic instructional guidelines for supporting refugee youth. Specific areas that should be explored include strategies for supporting ELLs and opportunities to help students' find connections between their cultural backgrounds and the curriculum that is being taught. Trauma-informed practices and attentiveness to providing safe learning environments that include secured facilities and appropriate supervision should also be considered.

\section{Recommendations for Future Research}

While this documentary research provided insight into the experiences of adolescent refugee youth who attended afterschool programs for literacy support, there were several limitations from the study. First, the documentary research was limited to refugee youth from two specific regions, Latin America and Africa. A larger sample size that represents students from multiple geographical regions is recommended to further our understanding of students' multicultural perspectives and experiences. Second, students from this study 
attended homework programs with students and tutors similar to their cultural backgrounds. Further research is needed to determine the experiences of refugee youth attending homework programs with participants and tutors from differing cultural backgrounds. Third, the homework clubs and tutorial programs were affiliated with organizations that were not directly affiliated with the students' schools. More investigation is needed to understand the experiences of refugee youth who attend schoolsponsored afterschool programs. Fourth, although elements from CRT and LEAD practices were organically present during tutoring support, tutors did not receive formal training in either practices during this study. Further research is needed to understand the experiences of refugee youth who work with tutors who are formally trained in CRT and LEAD practices. Lastly, the student participants from the study self-selected to receive tutorial support. More research is needed to investigate the experiences of youth who are mandated to attend tutorial services.

\section{Implications for Educational Leadership}

The findings from the documentary research identify several underlying issues that should be examined to help provide refugee youth with positive learning experiences and safe educational learning environments. First, educational leaders and policymakers are encouraged to reexamine current policies that have the potential to exclude or dissuade refugee families from accessing resources due to the citizenship status. Instead, educational leaders and policymakers should consider developing an established network of resources that immigrant families can readily access, such as afterschool academic support programs, mental health services, and free grocery or food bank services. Second, 
educational code and research-based support structures for refugee youth should be included within teacher and administrator preparation programs to strengthen the policies and instructional practices for supporting this student population. Consideration should also be given to understanding the educational code for supporting refugee foster youth.

Overall, educational leaders and policy decision makers should focus on creating or revising policies that are inclusive and supportive of refugee communities rather than create or re-enforce policies that seek to exclude and create barriers.

\section{Conclusion}

As U.S. refugee policies continue to evolve, it is critical that educational leaders and policy decision makers continue to shape and revise policies that reflect the needs of students within the U.S. school systems. Although the findings from the documentary research are limited to the subjects who participated in the study, school site administrators and educators are encouraged to explore how afterschool programs, culturally relevant, and TIPs can be used as additional support structures for providing literacy support and creating safe learning environments.

My personal background does not include the refugee experience found in the literature; however, I am a first-generation immigrant who grew up in a household with migrant parents who sought agricultural employment working in the fields and canneries across several regions and states. During my upbringing, I encountered classmates and their family members who did not have necessary documentation, access to the English language, understanding of the U.S. educational system, or financial resources to access educational resources to help them succeed in school. However, it was through the help 
of caring educators, administrators, and counselors, like the tutors mentioned in this study, that me and my classmates were provided with the tools necessary to succeed in our education. 


\section{References}

Au, K. H., \& Kawakami, A. J. (1994). Cultural congruence in instruction. In E. R. Hollins, J. E. King, \& W. C. Hayman (Eds.), Teaching diverse populations: Formulating a knowledge base (pp. 5-23). Albany: State University of New York Press.

Banks, J. B., \& Banks, C. A. M. (Eds.). (1995). Handbook of research on multicultural education. New York, NY: Macmillan.

Barajas, J. (2018). How Trump's family separation policy became what it is today. $P B S$. Retrieved from https://www.pbs.org/newshour/nation/how-trumps-familyseparation-policy-has-become-what-it-is-today

Blaustein, M. E., \& Kinniburgh, K. M. (2010). Treating traumatic stress in children and adolescents: How to foster resilience through attachment, self-regulation, and competency. New York, NY: Guilford Press.

Bolter, J., \& Chishti, M. (2019). The travel ban at two: Rocky implementation settles into deeper impacts. Retrieved from the Migration Policy Institute website: https://www.migrationpolicy.org/article/travel-ban-two-rocky-implementationsettles-deeper-impacts

Brown, J., Miller, J., \& Mitchell, J. (2006). Interrupted schooling and the acquisition of literacy: Experiences of Sudanese refugees in Victorian secondary schools. Australian Journal of Language and Literacy, 29, 150-162. Retrieved from https://www.researchgate.net/publication/238065807

Brown-Jeffy, S., \& Cooper, J. (2011). Toward a conceptual framework of culturally relevant pedagogy: An overview of the conceptual and theoretical literature. Teacher Education Quarterly, 38, 65-84. Retrieved from https://files.eric.ed.gov/fulltext/EJ914924.pdf

California Department of Education. (2010). DataQuest. Retrieved from http://www.cde.ca.gov/ds/

California Department of Social Services - Refugee Programs Bureau. (2017). Refugee arrivals into California counties federal fiscal year 2013-2016. Retrieved from www.cdss.ca.gov/Portals/9/Refugee/Arrivals/2013-2017_FiveYear_Arrivals_by_County_and_Year.pdf?ver=2018-05-23-154831-343 
Cowger, S., Bolter, J., \& Pierce, S. (2017). The first 100 days: Summary of major immigration actions taken by the Trump administration. Retrieved from the Migration Policy Institute website: https://www.migrationpolicy.org/research/first-100-days-summary-majorimmigration-actions-taken-trump-administration

Cravey, A., \& Petit, M. (2014). Media pedagogy in action: The making of the virgin appears in La Maldita Vecindad. Journal of Geography, 113, 68-77. doi:10.1080/00221341.2013.825003

Cummins, J. (1981). Bilingualism and minority-language children. Toronto, Ontario, Canada: The Ontario Institute for Studies in Education.

Dods, J. (2015) Bringing trauma to school: Sharing the educational experience of three youths. Exceptionality Education International, 25, 112-135. Retrieved from https://ir.lib.uwo.ca/eei/vol25/iss1/6

Espino, J., Fabiano, L., \& Pearson, L. M. (2004). Citizen schools: Evidence from two student cohorts on the use of community resources to promote youth development. Washington, DC: Policy Studies Associates. doi:10.17226/10022

Foster, M. (1995). African American teachers and culturally relevant pedagogy. In J. A. Banks \& C. A. M. Banks (Eds.), Handbook of research on multicultural education (pp. 570-581). New York, NY: Macmillan.

Garcia Coll, C., \& Magnuson, K. (1997). The psychological experience of immigration: A developmental perspective. In A. Booth \& A. C. Crouter (Eds.), Immigration and the family: Research and policy on U.S. immigrants (pp. 91-131). Hillsdale, NJ: Lawrence Erlbaum.

Gay, G. (2002). Preparing for culturally responsive teaching. Journal of Teacher Education, 53, 106-116. doi:10.1177/0022487102053002003

Gay, G. (2010). Culturally responsive teaching. New York, NY: Teachers College Press.

GovTrack.us. (2019). S. 643 - 96th Congress: Refugee Act of 1979. Retrieved from https://www.govtrack.us/congress/bills/96/s643

Graham, H. R., Minhas, R. S., \& Paxton, G. (2016). Learning problems in children of refugee background: A systematic review. Retrieved from http://pediatrics.aappublications.org/content/137/6/e20153994 
Harris, E. (1993). Economic refugees: Unprotected in the United States by virtue of an inaccurate label. American University International Law Review, 9, 269-307.

Retrieved from https://digitalcommons.wcl.american.edu/auilr

Huang, D., Kim, K. S., Marshall, A., \& Pérez, P. (2005). Keeping kids in school: An LA's BEST example study examining the long-term impact of LA's BEST on students' dropout rates. University of California, Los Angeles, National Center for Research on Evaluation, Standards, and Student Testing.

Iaquinta, A. (2006). Guided reading: A research-based response to the challenges of early reading instruction. Early Childhood Education Journal, 33, 413-418. doi:10.1007/s10643-006-0074-2

James, S., Quinn, G., \& Saidi, G. (2004). The new Americans [Film]. Kartemquin Films.

Kemmitt, A. (2007). Documentary stories for change: Viewing and producing immigrant narratives as social documents. The Velvet Light Trap, 60, 25-36. doi:10.1353/vlt.2007.0018

Kewel-Ramani, A., Gilbertson, L., Fox, M. A., \& Povasnik, S. (2007). Status and trends in the education of racial and ethnic minorities. Washington, DC: National Center for Education Statistics, U.S. Department of Education.

Kleinfeld, J. (1975). Effective teachers of Eskimo and Indian students. School Review, 83, 301-344. doi:10.1086/443191

Ladson-Billings, G. (1994). The dreamkeepers: Successful teachers of African-American children. San Francisco, CA: Jossey-Bass.

Ladson-Billings, G. (1995). Toward a theory of culturally responsive pedagogy. American Educational Research Journal, 32, 465-491. doi:10.3102/00028312032003465

Ladson-Billings, G. (2014). Culturally relevant pedagogy 2.0: A.K.A. the remix. Harvard Educational Review, 84, 74-84. doi:10.17763/haer.84.1.p2rj131485484751

Langman, J., \& Bayley, R. (2007). Untutored acquisition in content classrooms. In Z. Hua, P. Seedhouse, I. Wei, \& V. Cook (Eds). Language learning and teaching as social interaction (pp. 218-234). NY: Palgrave Macmillan. doi:10.1057/9780230591240_14 
Lauer, P. A., Akiba, M., Wilkerson, S. B., Apthorp, H. S., Snow, D., \& Martin-Glenn, M. (2006). Out-of-school time programs: A meta-analysis of effects for at-risk students. Review of Educational Research, 76, 275-313. doi:10.3102/00346543076002275

Learner, A. (2012). The educational resettlement of refugee children examining several theoretical approaches. Multicultural Education, 20, 9-14. Retrieved from https://files.eric.ed.gov/fulltext/EJ1014867.pdf

London, R., Gurantz, O., \& Norman, J. (2011). The effect of afterschool program participation on English language acquisition. Afterschool Matters, 13, 22-29. Retrieved from https://files.eric.ed.gov/fulltext/EJ980176.pdf

McBrien, J. (2005). Educational needs and barriers for refugee students in the United States: A review of the literature. Review of Educational Research, 75, 329-364. doi:10.3102/00346543075003329

McComb, E. M., \& Scott-Little, C. (2003). After-school programs: Evaluations and outcomes. Greensboro, NC: Serve. Retrieved from https://files.eric.ed.gov/fulltext/ED482765.pdf

Merriam, S. B., \& Tisdell, E. J. (2016). Qualitative research: A guide to design and implementation (4th ed.). San Francisco, CA: Jossey-Bass.

Michael-Chadwell, S. (2011). Examining the underrepresentation of underserved students in gifted programs from a transformational leadership vantage point. Journal for the Education of the Gifted, 34, 99-130. doi:10.1177/016235321003400105

Migration Policy Institute. (2015). In-country refugee processing in Central America: A piece of the puzzle. Retrieved from https://www.migrationpolicy.org/research/country-processing-central-americapiece-puzzle

Migration Policy Institute. (2017). How are refugees faring? Integration at U.S. and state levels. Washington, DC: Author.

Miles, J., \& Bailey-McKenna, M. (2017). Giving refugee students a strong head start: The LEAD program. TESL Canada Journal, 33(10), 109-128. doi:10.18806/tesl.v33i0.1249

Miller, J. (2009). Teaching refugee learners with interrupted education in science: Vocabulary, literacy and pedagogy. International Journal of Science Education, 31, 571-592. doi:10.1080/09500690701744611 
Montero, M., Newmaster, S., \& Ledger, S. (2014). Exploring early reading instructional strategies to advance the print literacy development of adolescent SLIFE. Journal of Adolescent \& Adult Literacy, 58, 59-69. doi:10.1002/jaal.318

Morland, L. (2007). Promising practices in positive youth development with immigrants and refugees. The Prevention Researcher, 14(4), 18-20. Retrieved from https://www.researchgate.net/publication/234754373

Naidoo, L. (2009). Developing social inclusion through afterschool homework tutoring: A study of African refugee students in Greater Western Sydney. British Journal of Sociology of Education, 30, 261-273. doi:10.1080/01425690902812547

Nation, P. (2001). Learning vocabulary in another language. Cambridge, England: Cambridge University Press.

Neuman, S. (2010). Empowered. Educational Leadership, 67, 30-36. Retrieved from http://www.ascd.org/publications/educationalleadership/apr10/vol67/num07/Empowered-After-School.aspx

Obama, B. (2015). Weekly Address: This Thanksgiving, Recognizing the Greatness of American Generosity [Video]. Retrieved from https://obamawhitehouse.archives.gov/the-pressoffice/2015/11/26/weekly-address-thanksgiving-recognizing-greatnessamerican-generosity

Office of Refugee Resettlement. (2017). Refugee arrival data. Retrieved from https://www.acf.hhs.gov/orr/resource/refugee-arrival-data

Ogilvie, G., \& Fuller, D. (2017). Restorative justice pedagogy in the ESL classroom: Creating a caring environment to support refugee students. TESL Canada Journal, 33, 86-96. doi:10.18806/tesl.v33i0.1247

Paris, D. (2011). Language across difference: Ethnicity, communication, and youth identities in changing urban schools. Cambridge, England: Cambridge University Press.

Paris, D., \& Alim, H. (2014). What are we seeking to sustain through culturally sustaining pedagogy? A loving critique forward. Harvard Educational Review, 84, 85-100. doi:10.17763/haer.84.1.9821873k2ht16m77

Petrarca, D., \& Hughes, J. (2014). Mobilizing knowledge via documentary filmmakingIs the academy ready? McGill Journal of Education, 49, 561-581. doi: $10.7202 / 1033547 \mathrm{ar}$ 
Pierce, S., Bolter, J., \& Selee, A. (2018). Trump's first year on immigration policy: Rhetoric vs. reality. Retrieved from the Migration Policy Institute website: https://www.migrationpolicy.org/research/trump-first-year-immigration-policyrhetoric-vs-reality

Rahn, J. (2008). Chapter 25 digital content: Video as research. In A. Cole \& J. Knowles (Eds.), Handbook of the arts in qualitative research: Perspectives, methodologies, examples, and issues (pp. 299-312). Thousand Oaks, CA: Sage.

Record-Lemon, R., \& Buchanan, M. (2017). Trauma-informed practices in schools: A narrative literature review. Canadian Journal of Counselling and Psychotherapy, 51, 286-305. Retrieved from https://cjc-rcc.ucalgary.ca/article/view/61156/pdf

Refugee Act of 1979 (1980 - S. 643). (2019). Retrieved from https://www.govtrack.us/congress/bills/96/s643

Refugee Education Assistance Act of 1980 (1980 - H.R. 7859). (2019). Retrieved from https://www.govtrack.us/congress/bills/96/hr7859

Refugee Processing Center. (2017). Department of State Bureau of Population, Refugees, and Migration Office of Admissions-Refugee Processing Center summary of refugee admissions. Retrieved from http://archives.doe.k12.ga.us/DMGetDocument.aspx/OST_Observation_Instrume nt1.pdf?p=6CC6799F8C1371F66C960E9B2653ACB287C8EA5B92175D39AB3 42CE18BF5632B\&Type $=\mathrm{D}$

Roberts, A., \& Locke, S. (2017). Tending school: A forum on the trending experiences of refugee and immigrant students in the U.S. Interchange EduEthics, 32, 375-391. doi:10.1023/A:1014614617716

Roxas, K. (2008). Who dares to dream the American dream? Multicultural Education, 16, 2-9. Retrieved from https://files.eric.ed.gov/fulltext/EJ832221.pdf

Roxas, K. (2011). Creating communities working with refugee students in classrooms. Democracy \& Education, 19, 1-8. Retrieved from https://democracyeducationjournal.org/home/vol19/iss2/5/

Sung, Y., \& Chang, M. (2008). Center-based care for language minority students. Educational Research and Evaluation, 14, 445-463. doi:10.1080/13803610802337699

Szente, J., Hoot, J., \& Taylor, D. (2006). Responding to the special needs of refugee children: Practical ideas for teachers. Early Childhood Education Journal, 34, 15 20. doi:10.1007/s10643-006-0082-2 
Taylor, S., \& Sidhu, R. (2012). Supporting refugee students in schools: What constitutes inclusive education? International Journal of Inclusive Education, 16, 39-56. doi:10.1080/13603110903560085

Tillman, L. C., \& Scheurich, J. J. (Eds.). (2013). Handbook of research on educational leadership for equity and diversity. New York, NY: Routledge.

UN General Assembly. (1948). Universal declaration of human rights (217 [III] A). Retrieved from http://www.un.org/en/universal-declaration-human-rights/

United Nations High Commissioner for Refugees (UNCHR). (2010). Convention and protocol relating to the status of refugees. Retrieved from https://www.unhcr.org/3b66c2aa10.html

United Nations High Commissioner for Refugees (UNCHR). (2014). Country chapters: UNHCR resettlement handbook: The United States of America by the government of the United States of America. Retrieved from http://www.unhcr.org/protection/resettlement/4a2ccf4c6/unhcr-resettlementhandbook-country-chapters.html

United Nations High Commissioner for Refugees (UNHCR). (2016). Global trends forced displacement in 2015. Retrieved from http://www.unhcr.org/statistics/unhcrstats/576408cd7/unhcr-global-trends2015.html

U.S. Senate and House of Representatives. (1980). Refugee Education Assistance Act of 1980. Retrieved from https://www.gpo.gov/fdsys/pkg/STATUTE94/pdf/STATUTE-94-Pg1799.pdf

U.S. Department of Health \& Human Services. (2016). About school impact. Office of refugee resettlement: An office of the administration for children \& families. Retrieved from https://www.acf.hhs.gov/orr/programs/school-impact/about

Valenzuela, A. (1999). Subtractive schooling. Albany: State University of New York Press.

West, S. D., Day, A. G., Somers, C. L., \& Baroni, B. A. (2014). Student perspectives on how trauma experiences manifest in the classroom: Engaging court-involved youth in the development of a trauma-informed teaching curriculum. Children and Services Review, 38, 58-65. doi:10.1016/j.childyouth.2014.01.013

Westwood, P. (2001). Reading and learning difficulties. London, England: David Fulton. 
Woods, A. (2009). Learning to be literate: Issues of pedagogy for recently arrived refugee youth in Australia. Critical Inquiry in Language Studies, 6, 81-101. doi:10.1080/15427580802679468 


\section{Appendix A}

\section{Interview Protocol}

Interview \#:

Date:

Location:

\section{Script for Interviewing Student Participants}

Thank you for agreeing to participate in this interview. The reason for this interview is because I am creating a documentary about students from refugee backgrounds and what it is like to attend an afterschool program to receive help with your studies. I am interested in how the afterschool program helps you with improving your reading comprehension skills. I would also like to know your opinion about how the afterschool program provides a safe learning environment for you. Before we begin our interview, I wanted to give you a brief background about myself. My name is Analiza Filion, and I have been a Middle School Language Arts teacher for 10 years. I was a teacher in Hawaii, and now I am a teacher and Vice Principal at a Catholic School in Santa Clara. I am also a Doctoral Student at San José State University. The two goals of my documentary work are to help students receive the best support from their tutors and teachers when asking for help with reading comprehension skills and to help provide students with safe learning environments.

The interview will take approximately 20 minutes and are based on the questions that we have already discussed. However, if you feel uncomfortable answering a question, please let me know, and I will skip to the next one. I will be using a video 
camera and a voice recorder to record our interview. Even though you have agreed to participate in this interview, your participation is completely voluntary, which means that you may tell me to stop the interview at any time. When we are finished with the interview, you will have the opportunity to review the video and audio footage.

What questions do you have for me before we begin? Now that I have answered your questions, with your permission, I am going to turn on my recording equipment, and we will start the interview.

\section{Interview Guide}

\section{Background/Demographic Questions}

- What school do you go to?

- How long have you been there?

- What are three words to describe your personality?

- What is your ethnic background?

- What other languages do you speak other than English?

\section{School Experience}

- How is the new school year going for you so far?

- Can you describe to me what you like best about going to school?

- If you could change anything about your school, what would it be?

- What type of grades are you getting in Reading?

- What type of Reading homework does your teacher assign you?

- How does your teacher help you with your Reading homework?

- How does your teacher use your home language as part of the classroom instruction?

- Can you describe to me how your school uses your cultural background as part of the classroom instruction?

- Tell me a story about your favorite teacher from school.

\section{Afterschool Program Experience}

- How did you hear about the Afterschool Program?

- How long have you been coming here?

- What do you like best about coming here?

- Tell me a story about your favorite memory from here.

- If you could change anything about the Afterschool Program, what would it be?

- Tell me a story about your least favorite memory from here.

- How do the tutors help you with your Reading homework?

- How have the tutors helped you with your grades since you have been coming here?

- Tell me a story about your favorite tutor here. 
- Can you describe to me how the Afterschool Program uses your home language as part of the classroom instruction?

- Can you describe to me how the Afterschool Program uses your cultural background as part of the classroom instruction?

\section{Safety}

- Do you believe that your school provides a safe learning environment for students?

- Can you describe how your school creates a safe learning environment?

- Can you tell me a story about a situation where you did not feel safe at school?

- Can you tell me a story about someone who has helped you feel safe at school?

- What can the school do to create a safer learning environment for students?

- Do you believe that the afterschool program provides a safe learning environment for students?

- Can you describe how the afterschool program creates a safe learning environment?

- Can you tell me a story about a situation where you did not feel safe at the afterschool program?

- Can you tell me a story about someone who has helped you feel safe at the afterschool program?

- What can the afterschool program do to create a safer learning environment for students?

We have now reached the end of our interview. Thank you so much for your time.

You did a great job. Please let me know if you would like to see footage from the video or listen to the recording. 


\section{Appendix B}

\section{Interview Guide for Former Tutoring Student}

\section{Background/Demographic Questions}

- What are three words to describe your personality?

- What is your ethnic background?

- What other languages do you speak other than English?

\section{School Experience}

- Can you describe to me what you liked best about going to school?

- If you could change anything about your school, what would it be?

- What type of grades were you getting in Reading?

- What type of Reading homework did your teacher assign you?

- How did your teacher help you with your Reading homework?

- How did your teacher use your home language as part of the classroom instruction?

- Can you describe to me how your school used your cultural background as part of the classroom instruction?

- Tell me a story about your favorite teacher from school.

\section{Afterschool Program (Homework or Tutoring Assistance Experience)}

- How did you hear about the Afterschool Program?

- How long did you attend the program?

- What do you like best about going there?

- Tell me a story about your favorite memory from there.

- If you could change anything about the Afterschool Program, what would it be?

- Tell me a story about your least favorite memory from there.

- How did the tutors help you with your Reading homework?

- How did the tutors help you with your grades since going there?

- Tell me a story about your favorite tutor.

- Can you describe to me how the Afterschool Program used your home language as part of the classroom instruction?

- Can you describe to me how the Afterschool Program used your cultural background as part of the classroom instruction?

\section{Safety}

- Do you believe that your school provided a safe learning environment for students?

- Can you describe how your school created a safe learning environment?

- Can you tell me a story about a situation where you did not feel safe at school?

- Can you tell me a story about someone who has helped you feel safe at school?

- What can schools do to create safe learning environments for students?

- Do you believe that the afterschool program provided a safe learning environment for students?

- Can you describe how the afterschool program created a safe learning environment?

- Can you tell me a story about a situation where you did not feel safe at the afterschool program? 
- Can you tell me a story about someone who helped you feel safe at the afterschool program?

- What can the afterschool program do to create safer learning environment for students?

- How has participation in the afterschool program affected your experiences or opportunities as an adult? 


\section{Appendix C}

\section{Interview Guide for Program Director/Tutor}

- Please describe the services offered by your organization.

- What role do you play in the organization?

- Please describe the demographic background of your clients.

- What is the process for helping students enroll in their new school systems?

- Can you describe some of the challenges that students face with transitioning into the new school system?

- What are everyday challenges that students endure in their school environments?

- What educational resources are available to refugee youth?

- What other resources are available for refugee youth?

- What are the best strategies for helping students develop their literacy skills?

- Please describe the ideal support structures for developing caring and safe learning environments for students.

- What areas can school systems improve upon to support refugee youth in the classroom?

- Can you share a success story about one of the current or former students from your organization and the role that the organization played in helping him/her be successful? 


\section{Appendix D}

\section{Release for Participation in Documentary Film}

\section{Experiences of Adolescent Refugee Students Who Participate in Afterschool \\ Programs for Literacy Support}

I, the undersigned, hereby consent to use of my physical image and voice to be used in the educational documentary, Experiences of Adolescent Refugee Students Who Participate in Afterschool Programs for Literacy Support (working title) produced and directed by Analiza Filion. I understand that I have the option of using a fictitious name for the purpose of the documentary. This documentary is intended for use in classrooms, by educational agencies and organizations, and by educational and PBS (Public Broadcast System) television stations. In giving this consent, I hereby release Analiza Filion of any proprietary rights that I may have in regard to this production. I do not expect to be paid for my participation.

NAME

DATE

SIGNATURE

ADDRESS

If under the age of 18 , have parent or guardian complete the following:

NAME OF

PARENT/GUARDIAN

SIGNATURE

ADDRESS 